\title{
2000 Engineering Annual Summary
}

C. Gerich

May 24, 2001

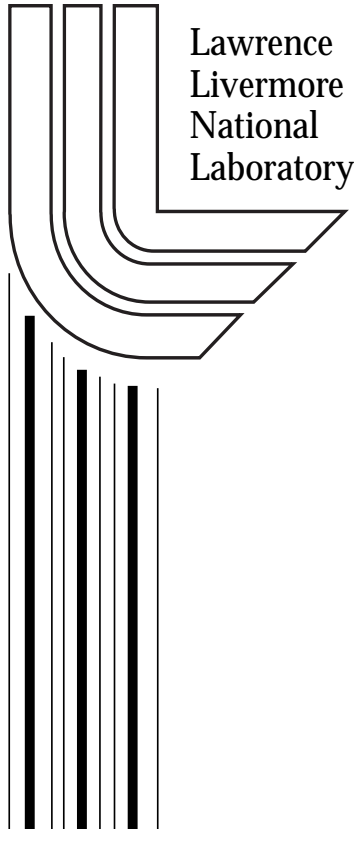




\section{DISCLAIMER}

This document was prepared as an account of work sponsored by an agency of the United States Government. Neither the United States Government nor the University of California nor any of their employees, makes any warranty, express or implied, or assumes any legal liability or responsibility for the accuracy, completeness, or usefulness of any information, apparatus, product, or process disclosed, or represents that its use would not infringe privately owned rights. Reference herein to any specific commercial product, process, or service by trade name, trademark, manufacturer, or otherwise, does not necessarily constitute or imply its endorsement, recommendation, or favoring by the United States Government or the University of California. The views and opinions of authors expressed herein do not necessarily state or reflect those of the United States Government or the University of California, and shall not be used for advertising or product endorsement purposes.

This work was performed under the auspices of the U. S. Department of Energy by the University of California, Lawrence Livermore National Laboratory under Contract No. W-7405-Eng-48.

This report has been reproduced directly from the best available copy.

Available electronically at http://www.doc.gov/bridge

Available for a processing fee to U.S. Department of Energy

And its contractors in paper from

U.S. Department of Energy

Office of Scientific and Technical Information

P.O. Box 62

Oak Ridge, TN 37831-0062

Telephone: (865) 576-8401

Facsimile: (865) 576-5728

E-mail: reports@adonis.osti.gov

Available for the sale to the public from

U.S. Department of Commerce

National Technical Information Service

5285 Port Royal Road

Springfield, VA 22161

Telephone: (800) 553-6847

Facsimile: (703) 605-6900

E-mail: orders@ntis.fedworld.gov

Online ordering: http://www.ntis.gov/ordering.htm

OR

Lawrence Livermore National Laboratory

Technical Information Department's Digital Library

http://www.llnl.gov/tid/Library.html 


\section{ENGINEERING ANNUAL SUMMARY}

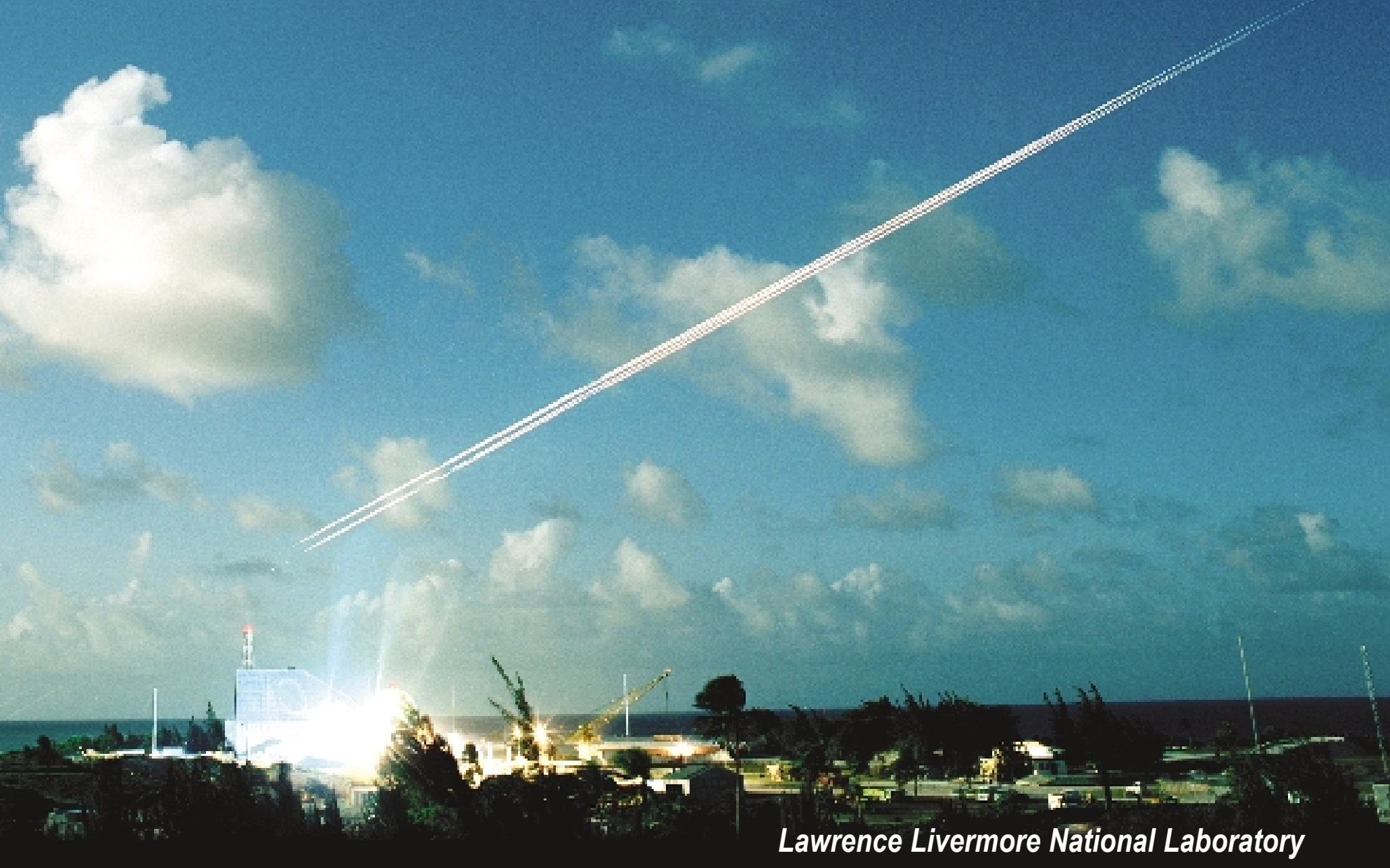




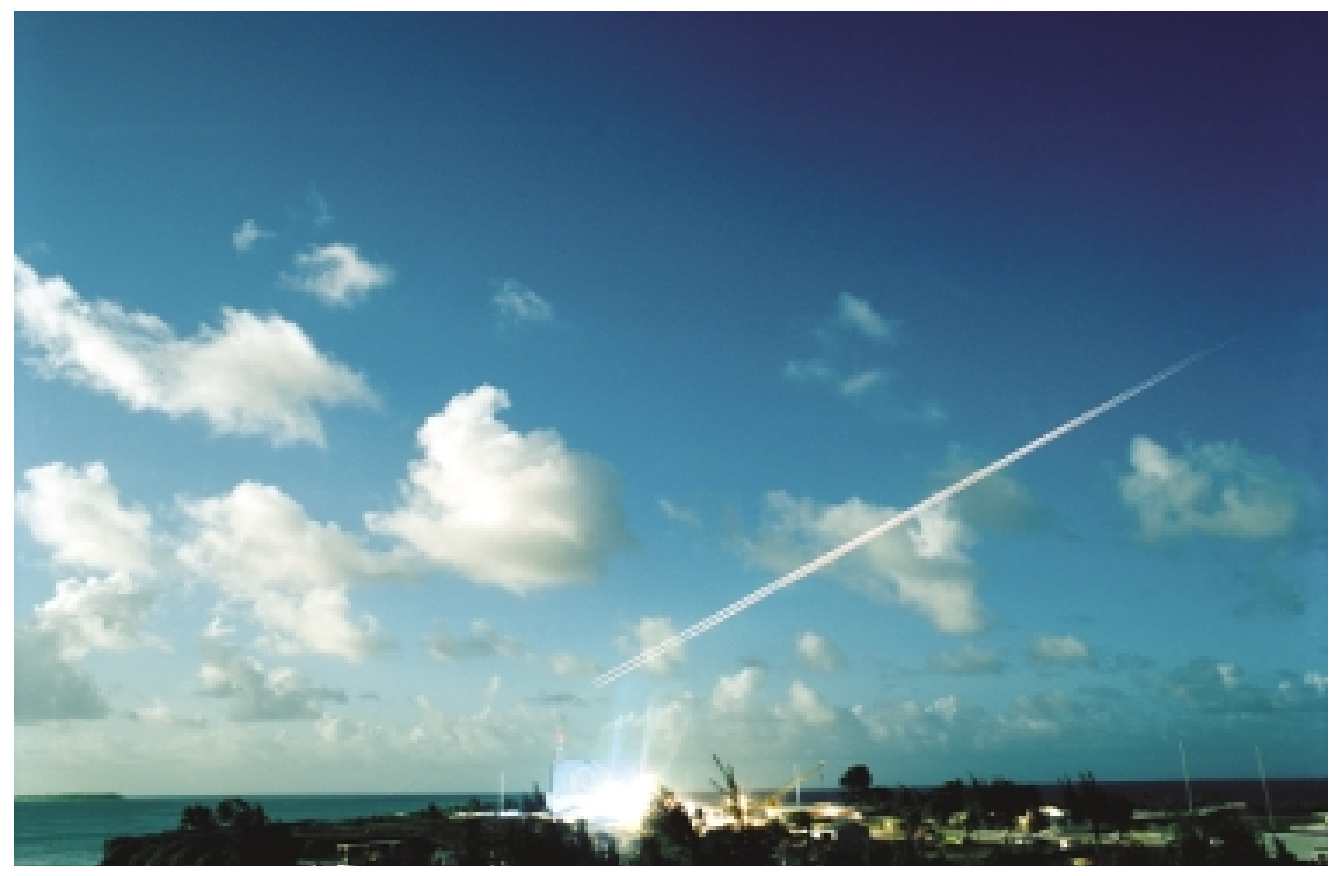

On the cover: Advanced diagnostics, developed by Engineering, are used to verify performance of reentry vehicles carried by intercontinental ballistic missiles under test at the Kwajalein Missile Range in the Marshall Islands.

This report has been reproduced directly from the best available copy.

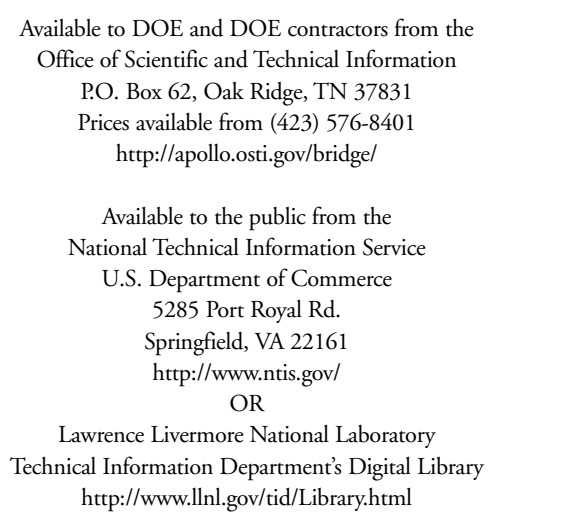

This document was prepared as an account of work sponsored by an agency of the United States Government. Neither the United States Government nor the University of California nor any of their employees makes any warranty, express or implied, or assumes any legal liability or responsibility for the accuracy, completeness, or usefulness of any information, apparatus, product, or process disclosed, or represents that its use would not infringe privately owned rights. Reference herein to any specific commercial product, process, or service by trade name, trademark, manufacturer, or otherwise, does not necessarily constitute or imply its endorsement, recommendation, or favoring by the United States Government or the University of California. The views and opinions of authors expressed herein do not necessarily state or reflect those of the United States Government or the University of California, and shall not be used for advertising or product endorsement purposes. 


\section{Contents}

2

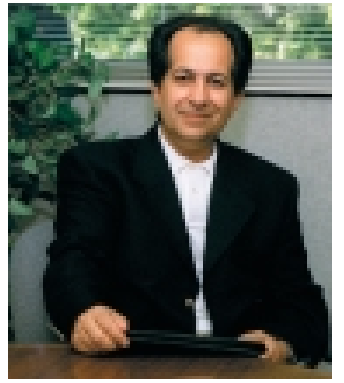

Message from the Associate Director

20

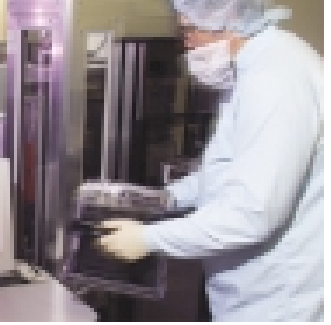

Business

Accomplishments

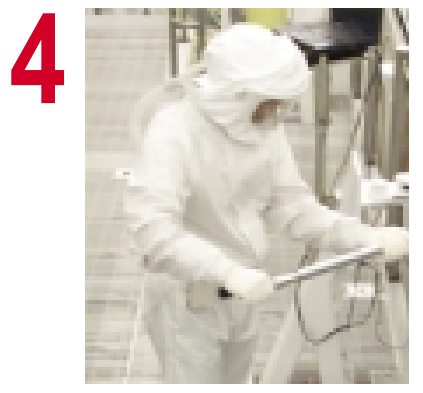

Profile of Engineering
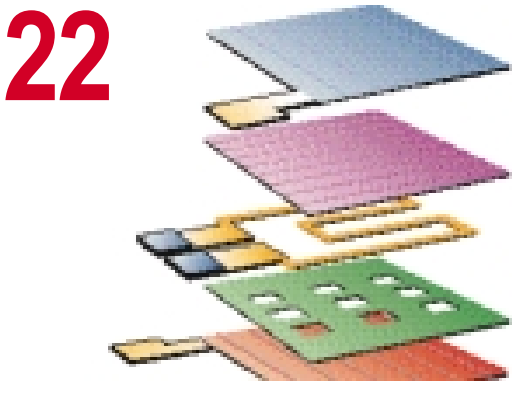

New Ventures
8

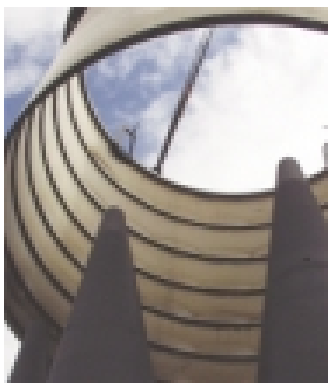

Technical Accomplishments

26

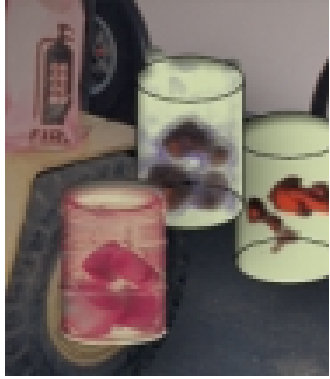

Honors and Awards
30

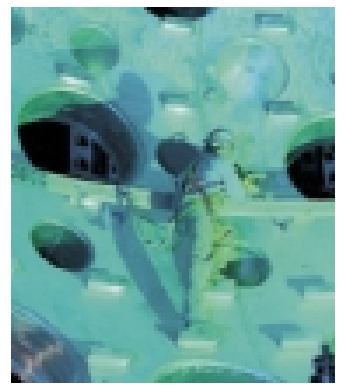

Future Priorities

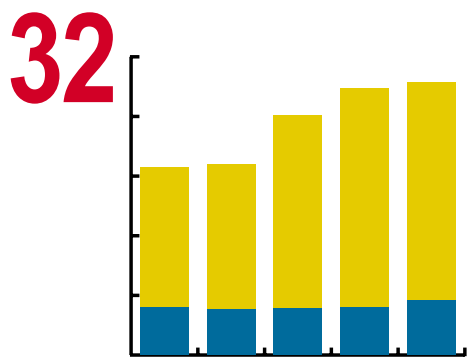

Engineering Statistics
33

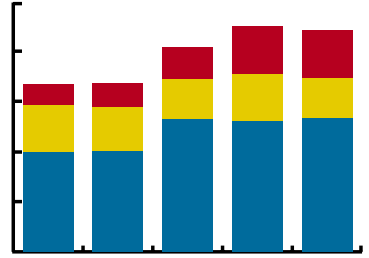

Laboratory Statistics 


\section{Message from the Associate Director}

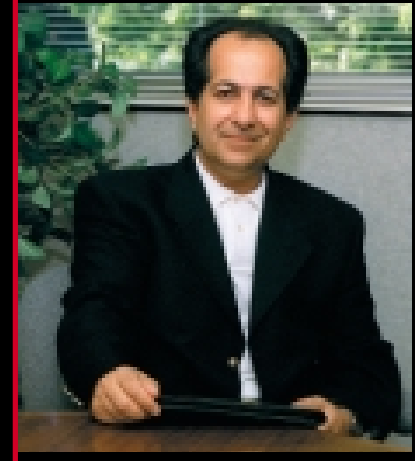

Spiros Dimolitsas is the Associate Director for Engineering.
T.T Torkforce issues dominated calendar year 2000 for Engineering at Lawrence Livermore National Laboratory. To meet critical project milestones, we were required to reassign a number of our employees to the Laboratory's largest project, the National Ignition Facility (NIF), as it rebaselined its plan to meet congressional and Department of Energy (DOE) approvals. At the same time, we were required to keep an ample, well-tuned workforce on other high-priority defense and national security projects.

We encountered, for the first time in our history, an elevated rate of attrition from our ranks - from single to double digits - due in part to the appeal and growth of high tech in our area of the country, as well as the aging of our own workforce. As demand peaked for our engineers, technicians, and craftspeople, we found ourselves with fewer employees. To meet increasing needs for staffing, we began a robust recruiting program that should start early next year and launched several new ventures, including a leadership development program and a project management skills-building institute.

The Laboratory is in a state of flux now, with many diverging priorities and several key leadership positions open. The Laboratory is also in a transitional mode with the United States government, as the new National Nuclear Security Agency, our largest customer, under General John Gordon, assumes duties formerly held by DOE. As a result, our work in Engineering this year reflected changing leadership and occasionally competing priorities.

In the defense area, we continued work on the W87 weapon refurbishment, on schedule for certification and delivery to the Air Force next year. Following the first two underground subcritical tests in 1999, additional tests were conducted in 2000, with a sustained 100-percent data-capture rate. Our Technical Accomplishments section provides details on the W87 life extension program and the OBOE weapons tests at the Nevada Test Site. In the coming year, we plan to take an active role in the W80 refurbishment for the nation's nuclear stockpile.

In the lasers area, we revised and delivered detailed designs for the newly rebaselined $\$ 2.2$ billion NIF super laser, paving the way for the procurement of components and structures for what is one of the largest high-tech construction projects in the world. We have aggressively staffed this project and instituted a more rigorous design review process to ensure the execution of a high-quality engineering process. The Technical Accomplishments section describes our work on the NIF amplifiers and integrated computer control system. 
On another front, by combining our competence in information systems, communications, and networking, we have helped establish the Laboratory as a leader in information-systems vulnerability analysis. Similarly, efforts in medical devices paid off with significant advances in ultrasonic imaging technologies. Engineering personnel were also awarded an R\&D 100 Award for work in passive/active tomography, and Engineering's electronics manufacturing attained an International Standards Organization 9002 certification. Institutionally, Engineering was responsible for managing the Laboratory's annual charity drive, which netted an all-time-high donation of $\$ 1.26$ million to national and local organizations.

While this report reviews our 2000 accomplishments, you can learn more about our 2001 activities by visiting our new Website at http://www-eng.llnl.gov. I can assure you that although we are moving at a faster-than-usual pace, we are meeting our milestones and creating exciting new ventures.
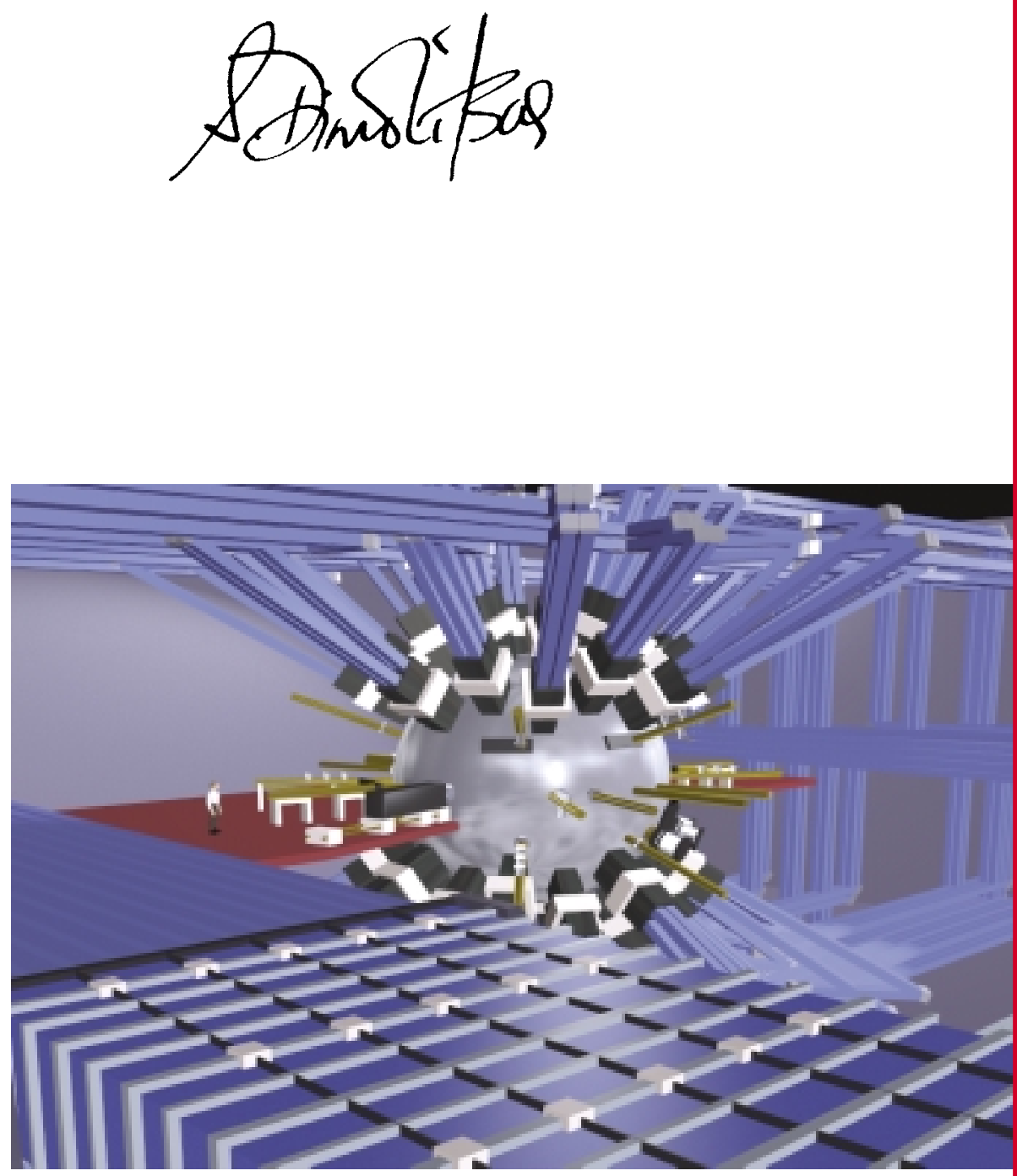

Artist's rendition of a closeup of the National Ignition Facility laser beams as they approach the target chamber with 192 lasers coming in simultaneously towards a target. 


\section{Profile of Engineering}

ur mission is to turn physics ideas into reality, that is, the abstract into the concrete, theory into application. In actuality, this means Engineering serves as the Laboratory's keystone by:

- Designing and building complex instruments and machines ready for production, such as diagnostics for mounting on missile test flights, portable sensors for detecting chemical and biological agents in the field, or weapons for the United States' nuclear stockpile (our main business).

- Designing and helping construct most of the Laboratory's unique test facilities, such as those where weapons are environment- and/or performance-tested and facilities where new manufacturing processes are developed.

- Conducting research in advanced, broad-application technologies that enhance the Laboratory's ability to pursue its mission.

National Ignition Facility (NIF) workers assemble amplifier housings-in a Class- 100 clean room that is 10 to 100 times cleaner than the aerospace environment in which satellites are constructed-prior to installing them in NIF.

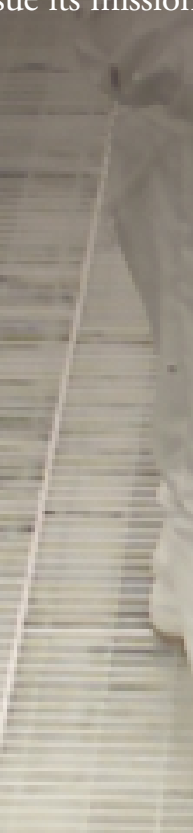


Through our competence, Xtreme Engineering, we undertake projects with high technical risk where we integrate and extend technologies concurrently and then push them to their extreme, such as building very large structures but aligning them with extreme precision. As we extend these technologies, we push the boundaries of engineering capabilities at both poles: microscale and ultrascale.

Today, for example, we are building the National Ignition Facility (NIF), a stadium-size facility with more precision optics than all the world's telescopes combined, incorporating 5100 tons of steel structures aligned at a hundredth-of-an-inch precision. In NIF, 192 laser beams will produce up to 500 terawatts of power ( 5 times the power output of the United States) for a billionth of a second.

\section{Engineering expertise}

The Laboratory is a facility owned by the Department of Energy; operation is contracted out to the University of California. The Laboratory's main mission is to address national security needs through the application of science and technology, with emphasis on the design, fabrication, and performance certification of nuclear weapons.

Almost one-third of the Laboratory's 6800 full-time employees work for Engineering. Our current staff of approximately 2000 combines expertise in mechanical, nuclear, chemical, electrical, electronics, computer, materials, civil, and other types of engineering.

For clients inside and outside the Laboratory, Engineering functions as a multidisciplinary organization with expertise in most of the major engineering fields. Engineering personnel simulate engineering systems, improve systems designs, and test performance. In addition, Engineering manages numerous large and small projects requiring complex interactions among many scientific disciplines.

Engineering's core competencies focus on:

- Integrated engineering of large, complex, applied physics systems

- Large, complex computation modeling and simulation

- Microscale engineering

- Measurement science at extreme dimensionalities 
Engineering's core competencies and their associated activity areas

\begin{tabular}{|c|c|c|c|}
\hline $\begin{array}{l}\text { Integrated engineering of large, } \\
\text { complex, applied physics systems }\end{array}$ & $\begin{array}{l}\text { Large, complex computation } \\
\text { modeling and simulation }\end{array}$ & Microscale engineering & $\begin{array}{l}\text { Measurement science at } \\
\text { extreme dimensionalities }\end{array}$ \\
\hline $\begin{array}{l}\text { - Nuclear and advanced conven- } \\
\text { tional weapons engineering } \\
\text { - Nuclear materials disposition } \\
\text { - Laser systems engineering } \\
\text { - Isotope separator engineering } \\
\text { - Safety-critical control systems } \\
\text { - Accelerator and particle detec- } \\
\text { tor systems engineering } \\
\text { - Field engineering } \\
\text { - Security control systems } \\
\text { - Adaptive optics } \\
\text { - Electronic commerce and con- } \\
\text { current engineering systems }\end{array}$ & $\begin{array}{l}\text { - Structural, thermal, and fluid } \\
\text { system analysis and design } \\
\text { - Nonlinear systems modeling } \\
\text { - Biological systems modeling } \\
\text { - Accelerator and microwave elec- } \\
\text { tronics analysis and design } \\
\text { - Antenna modeling } \\
\text { - Nuclear and electromagnetic } \\
\text { radiation effects } \\
\text { - Integrated photonics } \\
\text { - Information systems vulnera- } \\
\text { bility analysis and operations } \\
\text { - Transportation vehicles, sys- } \\
\text { tems, and infrastructure } \\
\text { - Natural hazards assessment } \\
\text { and mitigation }\end{array}$ & $\begin{array}{l}\text { - Precision, brittle material } \\
\text { fabrication } \\
\text { - High-precision optics } \\
\text { - High-precision diagnostic } \\
\text { instruments } \\
\text { - Miniaturized, integrated } \\
\text { analytical biological and } \\
\text { chemical systems } \\
\text { - Medical microinstruments } \\
\text { and microtools } \\
\text { - Genome sequencing instru- } \\
\text { mentation } \\
\text { - Optoelectronic communi- } \\
\text { cation devices }\end{array}$ & $\begin{array}{l}\text { - Real-time data acquisition and } \\
\text { processing } \\
\text { - Transient diagnostics } \\
\text { - Remote characterization and } \\
\text { detection systems } \\
\text { - Ultralow-power, precision } \\
\text { proximity radar } \\
\text { - Adaptive sensors and networks } \\
\text { - Nondestructive evaluation } \\
\text { - Accelerated materials aging } \\
\text { - Biomedical imaging } \\
\text { - Geologic signal processing and } \\
\text { analysis } \\
\text { - Subsurface (including under- } \\
\text { ground) imaging } \\
\text { - Environmental monitoring } \\
\text { and characterization }\end{array}$ \\
\hline
\end{tabular}




\section{Facilities and special capabilities}

Engineering manages 26 facilities. These total 780,000 gross square feet, with 70 percent dedicated to working engineering laboratories, shops, and computer equipment and storage space. In addition, Engineering operates 34 buildings and magazines at Site 300, a nearby test site.

Within these facilities, we have developed special capabilities that advance our technical expertise and boost leading-edge results. The following is a sampling of the highlights, with more detail and photographs on our Website at http://www-eng.llnl.gov.

- Our microfabrication building houses 3500 square feet of Class 10-1000 clean rooms for micromachining, silicon microelectronics, III-V semiconductor optoelectronics, and guided-wave photonics. Other labs provide material characterization and devicetesting capabilities, microscopic inspection, packaging, and electrical and optical testing of devices.

- Our Large-Optics Diamond-Turning Machine (LODTM) is one of the largest diamond-turning machines in existence, with capacity for parts up to 64 inches in diameter, 20 inches tall, and weighing up to 3000 pounds. The contouring accuracy of LODTM is 1 microinch root mean squared (rms). The machine, which can create mirror-surface finishes, is used for both machining and inspection operations.

- Our abilities in plasma and high-power systems allow us to design, construct, and test total systems, including the necessary support circuits, subsystems, and software. Several facilities support this work, such as an anechoic chamber and a large-scale test antenna.

- Our high-pressure lab is one of the most complete high-pressure design, fabrication, and testing facilities in the world.

- Our electronics manufacturing facilities (which were ISO 9002 quality certified this year) include central drafting, electronic fabrication/packaging, printed circuit load/surface mount technology, and the through-hole technology facility.

National Ignition Facility technicians use specially designed carts for ultraclean maintenance and assembly in the Amplab, the multimillion-dollar facility for testing the main amplifiers jointly developed by the Laboratory and the French. 


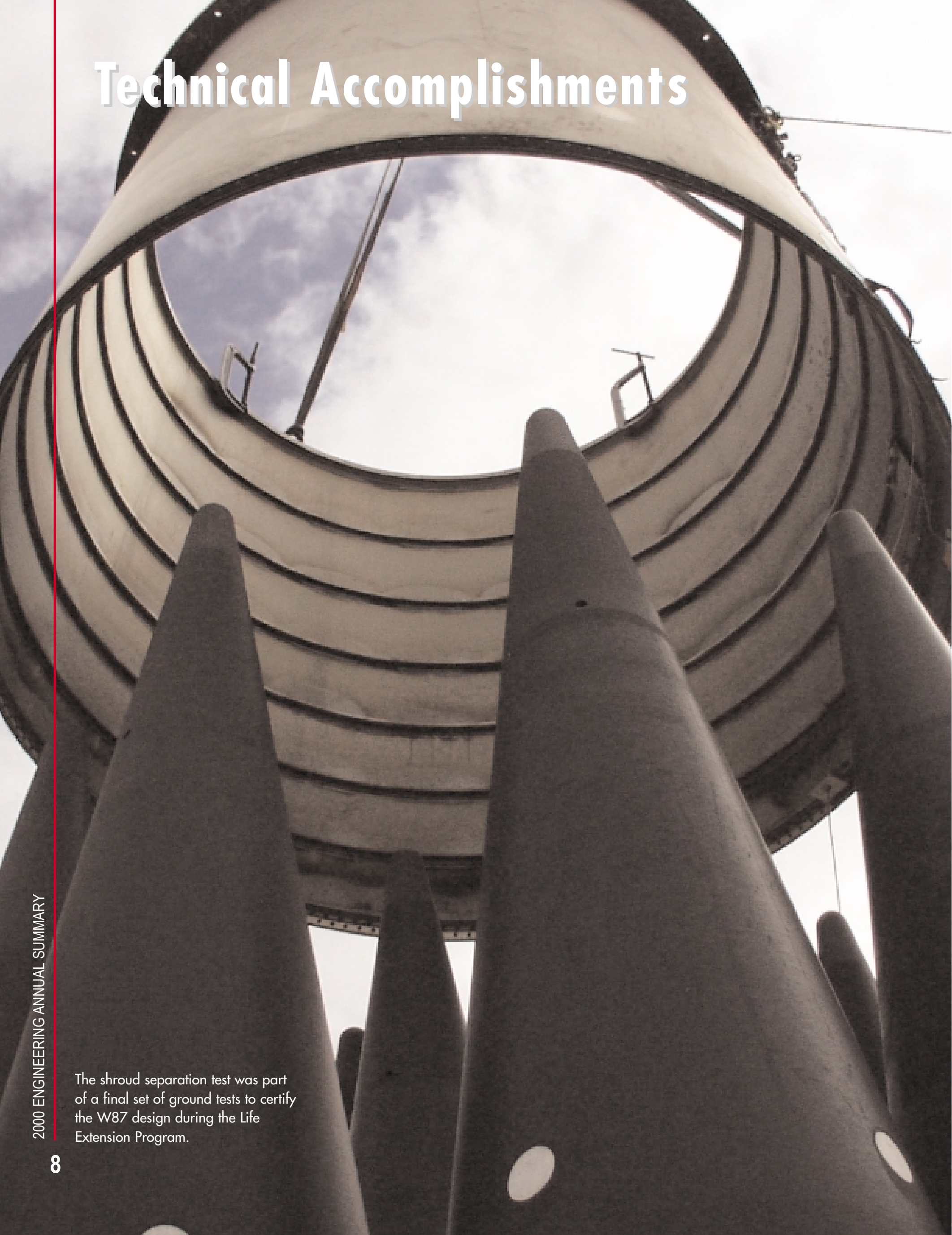




\section{W87 Life Extension Program continues}

The Laboratory maintains four systems in the active and inactive stockpile of nuclear weapons for our nation. Of these, the W87 is the weapons system with the most modern safety features and the first to undergo a life extension program as part of the Department of Defense/National Nuclear Security Administration (NNSA) effort to refurbish the enduring stockpile.

Refurbishment is a much more difficult task today because fully integrated (nuclear) tests of the modified warhead can no longer be performed. In addition, several of the original manufacturing plants or the same production capabilities are no longer available. Yet, the Laboratory Director, along with the Director of Los Alamos National Laboratory and the President of Sandia National Laboratory, must certify to the NNSA that these warheads will perform as intended. For the W87 certification, engineering analysis played an important role in both designing and conducting tests and predicting response to expected loads.

During 2000, we performed three types of tests on the W87 in preparation for certification: ground tests, a flight test, and a Retrofit Evaluation System Test (REST). The tests subjected the W87 to a comprehensive set of thermal/structural environments that a warhead normally experiences during its lifetime. These environments included modal surveys; simulated storage at the Pantex plant in Amarillo, Texas; ground shipment; air shipment; reentry system and powered flight vibration; shroud and reentry vehicle separation shocks; reentry vibration; and pitch-roll resonance accelerations.

The suite of ground tests was the most thorough and realistic environmental tests conducted on the W87 warhead to date.

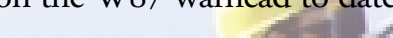


Flight tests were conducted from Vandenberg Air Force Base in California to Kwajalein, Marshall Islands, in the Pacific. The high-fidelity joint test assemblies flown demonstrated as-expected flight and functional performance. Laboratory down-range hydrophone and optic sensors were used at Kwajalein for evaluating the performance of the reentry vehicles. For the first time, these Laboratory sensors were used to perform the mandatory scoring function, and they provided data more accurate than previously collected.

Finally, a production life-extended warhead was disassembled and evaluated during the REST, which confirmed the quality of the new production process. With testing complete, certification of the W87 warhead is expected for 2001.

\section{OBOE continues successful subcritical experiments}

For the OBOE series of experiments, Laboratory and Bechtel Nevada workers lower the "cube," which contains plutonium and chemical explosives, into the heavily instrumented vessel.
OBOE, a series of 8 subcritical weapons tests, is part of a suite of 32 tests used to compare older materials and manufacturing processes with materials and processes available today to refurbish stockpile weapons systems. OBOE subcritical experiments for the past year studied the material properties of plutonium in a high-shock environment caused by a highexplosive detonation; 100 percent of available data was gathered. We played key technical and project management roles in fielding four new experiments at the Nevada Test Site: OBOE 2, 3, 4, and 5 .

OBOE 2, the first radiographic experiment to look at fragments removed from the surface in an expendable vessel, was completed in a record turn-around time of less than six weeks following OBOE 1. We used new masking techniques to gather needed data, and although the data collected was excellent, the need for a higher energy, compact x-ray source became obvious. We have begun plans for collaborative development of this source, which will eventually eliminate the need to mask and allow for direct measurement of fragments removed from the surface. OBOE 8 , planned for 2001, will test the new source.

OBOE 3, 4, and 5, which were holographic experiments to study the surface ejecta, returned high-quality data on 100 percent of the instrumentation channels, including the highest resolution holographic images of a plutonium ejecta cloud ever obtained. 
Holographic images of these experiments are computer-generated, and we will use them in many different ways, from viewing slices of the images to correcting the current advanced computing models based on data from similar experiments using surrogate materials.

This year, we also proved the expendable vessel strategy proposed last year by creating better, faster, and cheaper experiments. Today, diagnostic equipment is closer to an individual experiment, thus creating better resolution. Our turn-around time between experiments has been reduced from one year to six weeks. The containment vessels have reduced experiments costs from over $\$ 5$ million each to $\$ 2.5$ million.

New technologies were also introduced into the OBOE experiments this year. The Photonic Doppler Velocimeter, a Laboratory Directed Research and Development project, improved the time response of the Fabry-Perot velocimeter's measurements, allowing physicists to examine initial movement of plutonium characteristics in the experiments. Two emerging technologies, the Compact Marx Generator from the Laboratory and the Rod Pinch Diode from the Naval Research Laboratory, will be combined on OBOE 8 to produce a new moderate-energy $x$-ray source for future subcritical experiments.

\section{Key testing of NIF amplifiers begins}

At the heart of the National Ignition Facility (NIF) laser, two systems - a main amplifier and a power amplifier — work together to amplify the optical energy in each laser beam from 1 joule to 20,000 joules. We began the full-scale testing of a 2-megajoule, power-conditioning module and a single amplifier module in August 2000. This testing was a critical first step in the long process of verifying and demonstrating acceptable reliability of the complete amplifier system.

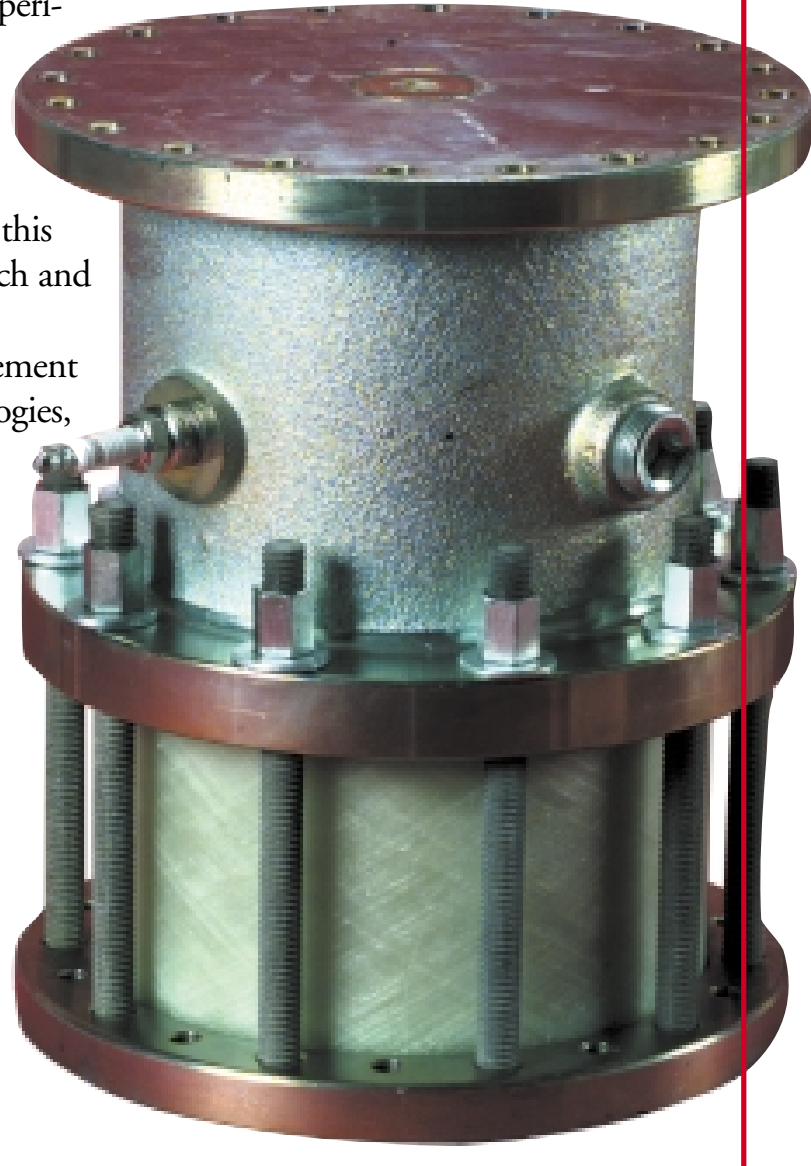

The NIF amplifier system provides approximately 50 times more output than the system on Nova, the Laboratory's most powerful laser prior to the NIF. The electrical energy required to drive the NIF amplifier system is provided by 192 power-conditioning modules. Each module converts the "wall-plug" power into 24,000-volt, 550,000-ampere pulses that energize the nearly 8000 flashlamps on NIF.

We completed successfully over 400 full-energy shots in the year 2000, with the goal of completing 20,000 full-energy system shots over the next year and a half to simulate the 30-year NIF lifetime. With each shot, we are addressing the last remaining issues to ensure the power-conditioning and the amplifiers work together reliably as a system and meet the performance requirements.
The spark-gap switch of the National Ignition Facility amplifier system switches 550 kiloamperes to deliver energy to flashlamps. 
In addition to demonstrating performance and reliability next year, we will evaluate several system issues, such as electromagnetic compatibility and system grounding. The operating test facility will also be used for training future NIF power-conditioning-system operators, refining specific safety procedures for the NIF facility, and developing maintenance schedules and procedures. This facility will help ensure a smooth transition from system design to full-scale amplifier system implementation and operation on NIF.

\section{NIF control system milestone met for FEIST}

Our Integrated Computer Control System (ICCS) team delivered controls for the third round of Front End Integrated System Tests (FEIST-3). The FEIST-3 deployment is the most comprehensive set of integrated NIF laser controls delivered to-date, providing the functionality needed to operate portions of the master oscillator, together

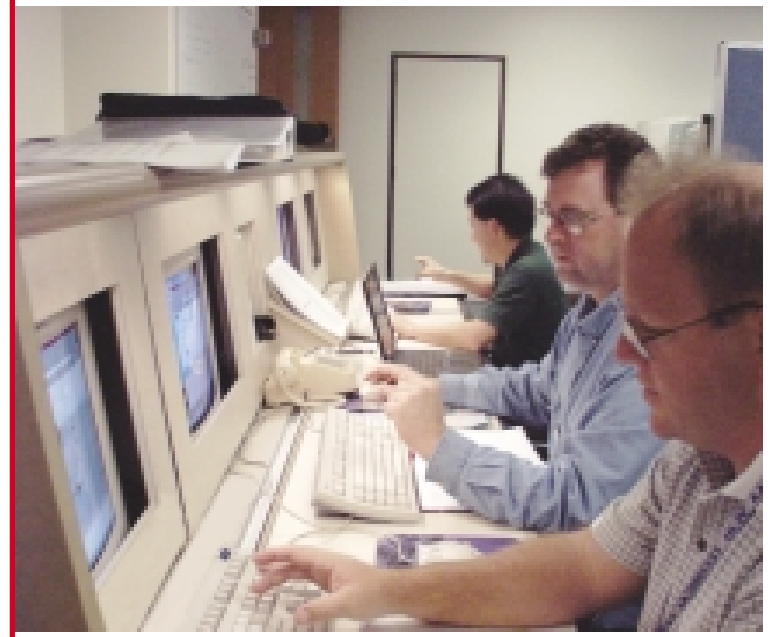
with the pre-amplifier module (PAM), input sensor package (ISP), timing, and video subsystems. FEIST-3 provides the capability to initiate a laser pulse in the master oscillator, propagate it through the PAM, and diagnose it with the ISP. Other high-level capabilities include laser "shot" coordination, automatic alignment of the PAM and ISP, and data archiving. FEIST-3 controls have been used to perform FEIST laser shots with output energies of more than 17 joules.

The FEIST-3 release, which was developed by over 30 engineers and computer scientists, consists of 66 computer programs within 14 integrated software products. With the new release, over 300,000 source lines of Ada and Java code are under configuration control in the entire ICCS inventory-approximately onethird of the code needed for the entire NIF control system. The

National Ignition Facility test engineers perform offline testing of the Prototype Injection Laser System controls on the Integrated Computer Control System testbed. release completed formal offline testing before being deployed in the FEIST laboratory, where we are conducting additional online integrated testing prior to NIF operations. We will also use the new software during validation of the laser hardware design.

FEIST-3 is a major revision of FEIST-2 software, delivered months earlier in 2000. It includes enhancements for system startup, shot cycle setup, shot data archiving, and error handling. It contains increased master oscillator functionality and performs automatic alignment of the preamplifier module using the input sensor package controlled by the alignment and video front-end processors. The preamplifier is controlled by a dedicated frontend processor interfaced to the multipass amplifier, power conditioning unit, and timing triggers accessed through the preamplifier module supervisor and graphical user interfaces. Shot archiving and monitoring of laser energy and power measured by devices in the input sensor package are performed through laser energy and power front-end processors. Fortyeight preamplifier modules and input sensors will be installed in NIF. 


\section{Successful flight tests produce high-quality hyperspectral infrared imaging data}

A team of Laboratory engineers and scientists fielded the hyperspectral infrared imaging spectrometer (HIRIS), an advanced Fourier transform imaging instrument developed by the Laboratory, in several successful flight campaigns to support NNSA's nuclear nonproliferation mission. The HIRIS captures pictures of the ground at invisible thermal infrared wavelengths in many bands (colors) at once, enabling analysts to characterize the different materials in a scene.

Last year, the HIRIS flew at 60,000 feet aboard NASA's WB-57F aircraft, an altitude more than 1.5 times higher than the average commercial airline flies. Using the data gathered, the HIRIS team was able to evaluate the scientific usefulness of this remote sensing technique. We in Engineering excel at developing systems that perform well in harsh environments, such as high-altitude flight with ambient air temperature of -55 degrees Fahrenheit and air pressure only one-tenth that at sea level.

Infrared hyperspectral imaging systems detect, locate, identify, and quantify invisible trace chemicals by their characteristic spectral signatures. The HIRIS does this by simultaneously providing spectral, spatial, and temporal information in the long wave infrared "fingerprint" regime. The HIRIS is a collaborative program among four organizations at the LaboratoryEngineering; Nonproliferation, Arms Control and International Security; Computation; and Chemistry and Materials Science_-Los Alamos National Laboratory; Pacific Northwest

National Laboratory; and the Remote Sensing Laboratory. HIRIS is sponsored by NNSA and is under development for a wide variety of remote sensing, nonproliferation, and environmental monitoring uses. Potential applications for the technology include gas characterization, military targets characterization, buried mine detection, biomedical imaging, and astronomical studies. 


\section{EUVL breakthrough ensures microchip designs of the future}

Engineer Mark Schmidt loads an optic into the Mag-4 multilayer deposition system used to coat optics for extreme ultraviolet lithography. Precision motion of the substrates allows coating four optics in a single run while maintaining the required atomic-level precision.
Extreme ultraviolet lithography (EUVL) technology was developed by a partnership of Lawrence Livermore, Sandia, and Lawrence Berkeley national laboratories and was funded by a semiconductor industry consortium of companies (Intel, Motorola, AMD, Micron, Infineon, and IBM) competing to print the next generation of the world's smallest computer chips. This year, advances in nanoscale precision optics and coatings helped boost our EUVL program in printing the tiny features required for advanced computer chip manufacturing. The prototype EUVL system successfully printed 100-nanometer features across a postage-stamp-size field. Previously, we could only print over a field the size of a pin head. Printing across the larger field is required to produce thousands of chips an hour.

Using our new Mag-4 optics coater, we achieved a coating thickness precision of 0.01 nanometers over 160-millimeter surfaces. Such precision is required for two reasons: to make all the optics in the system reflect at precisely the same wavelength and to preserve the precision aspheric shape of the optics. The new coater allowed us to coat four projection optics (compared to one) in one run and demonstrated the manufacturability of the process. The Mag-4 coater is a scaled-up version of Laboratory magnetron sputter deposition technology. It was built in partnership with Veeco Instruments.

In addition, we fabricated the precision optical substrates in partnership with SVGTinsley. The optics have carefully prescribed aspheric shapes with a surface figure accuracy of 0.25 nanometers. The Laboratory invented the specialized interferometers required to measure the shape of the optics accurately.
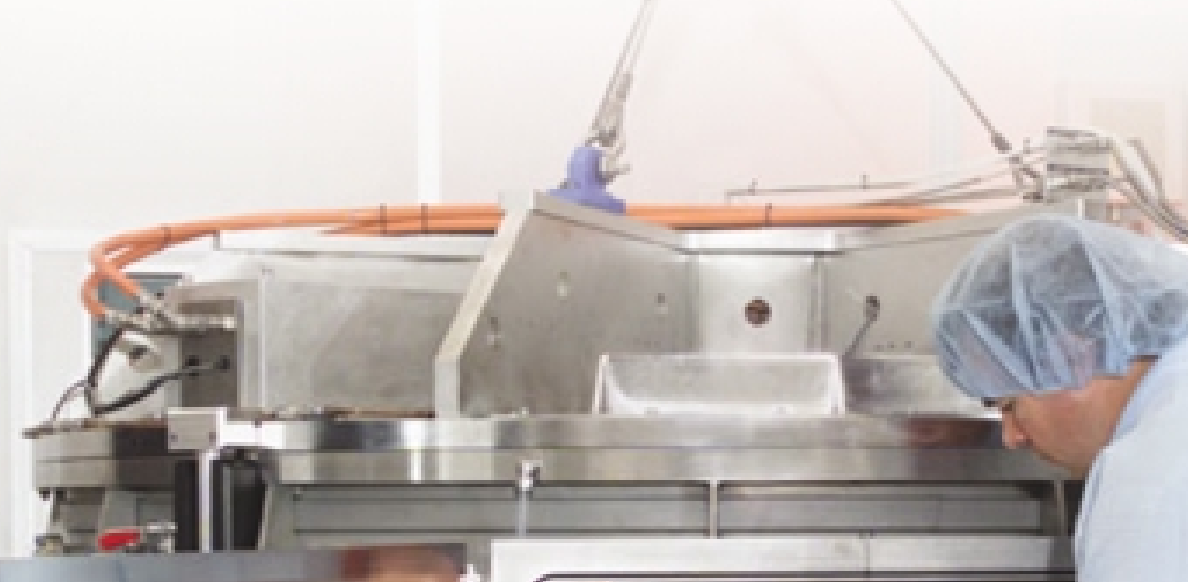
Our precision engineering team designed and fabricated the mechanical structure used to align the four optics. We were able to demonstrate the tiny nanometer-scale adjustments to the optics within a structure that is stable over time. We have also demonstrated the ability to transport the projection-optics camera to Lawrence Berkeley, where the alignment was certified with extreme ultraviolet light.

\section{Engineering Section receives first-class operation status-ISO 9002}

Our Electronics Engineering Manufacturing and Services Section received registration as being compliant with the International Standards Organization (ISO) 9002a worldwide benchmark for assuring high quality and customer satisfaction in production, installation, and service. We are one of the first within the NNSA national laboratories to receive registration for our Quality Management System.

Providing manufacturing and technical expertise throughout the Laboratory, our services include electronics and control system design; manufacturing and installation; infrastructure support for radio, video, and paging; and engineering support. Originally, we saw ISO 9002 compliance as a way to reduce expenses to our customers while increasing both customer satisfaction and quality of workmanship. It worked. Today, we can be counted on to say what we are going to do, do what we say, and keep good records. Any problems are solved internally. As the quality and reliability of our products and services increase, errors and customer complaints decrease.

Every six months, our Section will be re-audited by an agency registered with the American Society of Quality to ensure we continue to fully comply with the high standards set by the ISO. Our Section is committed to continue at this level of excellence by following a seven-step process: 1) document the processes, 2) develop and document additional processes needed for improvement, 3) install and implement the documented processes,

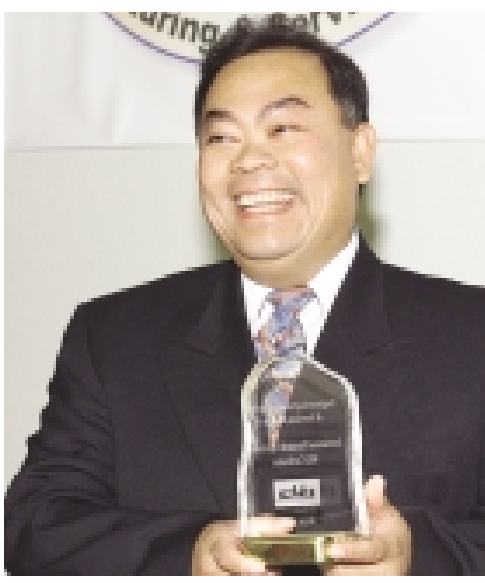

Engineer Ken Luu, who heads the Engineering Manufacturing and Services Section, accepted the International Standards Organization 9002 Award on behalf of his team. 4) check that the processes are being followed, 5) correct nonconformities, 6) review the Quality Management System procedures and processes, and 7) complete a verification surveillance audit performed by the certification registrar. 


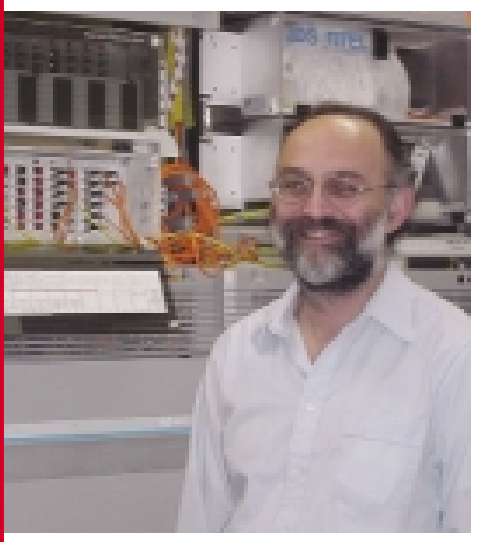

\section{NTON achieves even higher speeds}

At the Supercomputing and Communications 2000 Conference, the National Transparent Optical Network (NTON) consortium delivered even higher record speeds for data transfer, quadrupling its record speeds from 1999. Taking first place in two categories, our team demonstrated both the highest peak rate of 1.48 gigabits per second for an instantaneous transfer and the most data transferred over a 60-minute period- 562 megabits per second for a total of 252 gigabytes of data. Higher peak rates have been demonstrated through NTON; however, the conference limited links to 1.5 gigabits per second to accommodate business traffic.

Engineer George Pavel monitors the fiber-optic cables carrying the high-speed signals that the National Transparent Optical Network transmits.
During the conference challenge, our team demonstrated NTON's speed via a distributed visualization application. Data stored in one location was calculated in another location, with the actual graphic renderings displayed in a third location-the conference site in Dallas. This capability allows for the distribution of data storage, computing, and display systems at different locations. In effect, a computer workstation is being extended through the network, thus eliminating the need for duplicate hardware at each site. Data were accessible from all sites even though they were stored in several distributed locations. Since network speeds are very fast -1000 to 2000 times faster than a home cable modemworkers at distributed sites are able to manipulate data as if the data were on their own computer in their office.

In the coming year, our team will focus on deploying higher speed applications in high-energy physics, astrophysics, and medical informatics. NTON is a partnership between the Laboratory, Nortel Networks, GST Telecommunications, Sprint, and the Bay Area Rapid Transit system.

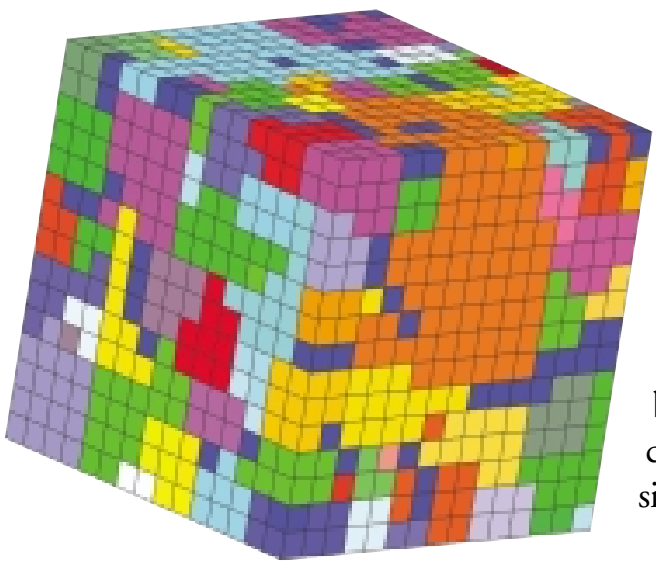

The unit material model of the grain microstucture is used to determine material properties. The average properties derived from the grain orientations determine the spin characteristics of the ejected material.

\section{Modeling capabilities improved for stockpile surveillance}

We are teaming with Chemistry and Materials Science and Physics and Advanced Technology to provide an understanding of fundamental aspects of dynamic material response in support of the Stockpile Surveillance Program. This activity is part of an effort to capture the behavior of materials from the basic atom to the crystalline structure and to characterize the engineering properties of the materials for use in numerical simulation codes.

Our focus in 2000 was to understand how the material microstructure causes a shaped charge to spin. We characterized the grains and orientations in a representative sample of an actual shaped-charge liner. Gathered data were used in a 3-D finite-element model by applying crystal plasticity theory to successfully predict the rotational response in representative sample problems. Our goal is to predict the rotation of the ejected material and the shaped charge using the measured crystalline properties of the shaped-charge liner. 
Next year, we plan to complete the full simulation of the formation process for the ejected material. This is part of an overall effort to address a unified theory of material behavior. Our ultimate objective is to provide better theories and models for behavior of nuclear stockpile materials, using computer-simulated models in lieu of expensive, complicated testing, such as the OBOE experiments.

\section{New generator promises more Department of Defense applications}

We fabricated an innovative, ultracompact, high-voltage generator in 2000. Because of its performance and compact size, this Marx-type generator is the enabling technology for a high-performance, $\mathrm{x}$-ray radiographic source supporting subcritical experiments at the Nevada Test Site. Multiple units of this generator have also been fabricated and delivered for evaluation in Department of Defense applications.

The ultracompact Marx generator is a sophisticated electrical device with an elaborate mechanical assembly. It incorporates high-performance components integrated into an extremely compact assembly. The construction provides an integrated support structure for all of the components, permitting operation in any orientation. The modular design can be sized as needed for a particular application. Units have been assembled with 4,10, and 30 stages and operated at levels up to 100 kilovolts per stage.

Future plans for the ultracompact Marx generator include use in our OBOE 8 experiment, as a diagnostic designed to produce a new moderate-energy $\mathrm{x}$-ray source for future subcritical experiments. Higher energy and voltages are also possible in the future as we advance compact Marx technology, which has potential uses in a variety of special pulsedpower applications, including high-voltage impulse sources, compact and portable $\mathrm{x}$-ray machines, particle beam injectors, table-top plasma radiation sources, and many other technologies.

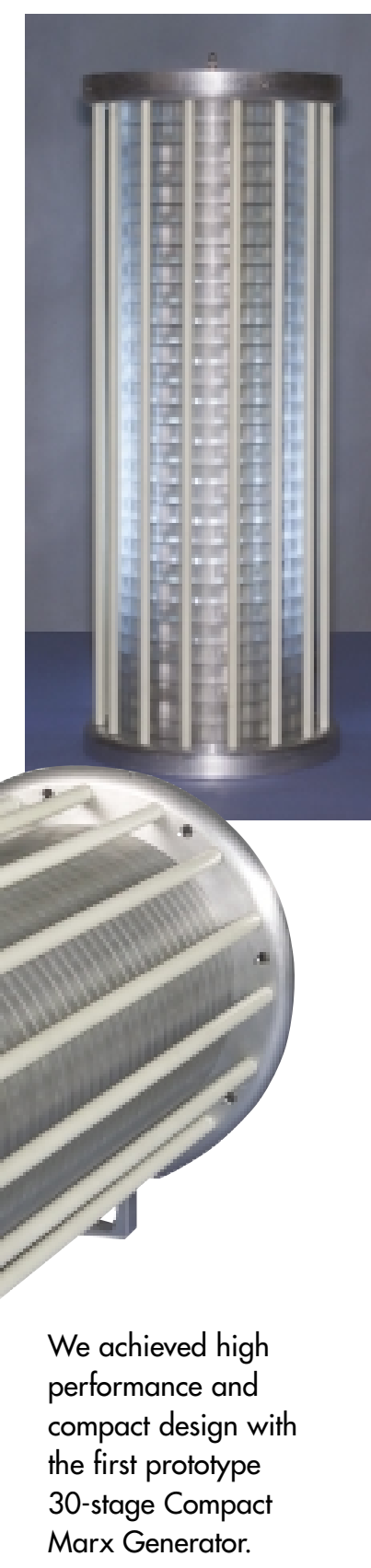




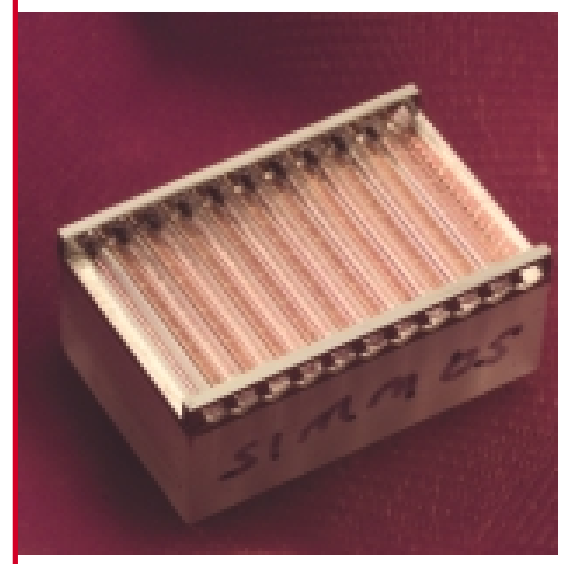

\section{Silicon microchannel-cooled laser-diode array pioneered}

We have developed a new semiconductor laser-diode array package using silicon fabrication technology (photolithography and wet chemical etching). With this new technology, making diode-pump arrays for solid-state-laser systems with upwards of 100-kilowatt output powers is now feasible. This development represents a 100 -fold increase over arrays fabricated using currently available packaging technologies. The new technology has improved both diode durability and performance, while decreasing the cost by a factor of three. Two patents have been awarded for this technology.

Laser-diode arrays are becoming increasingly attractive as pump sources for solid-state lasers because of their narrow-band emission, high efficiency, and long-term reliability.
In the past, high-average-power, diode-pumped, solid-state lasers were prohibitively expensive when used with commercially available technologies. In the new technology, we use silicon for the package because the extremely fine water passages required (30-micrometerwide microchannels) can be easily fabricated, as can the precision-located pads to which the laser-diode bars are attached. Microchannels are necessary for removing the intense waste heat generated by a laser so that only a small temperature increase occurs.

Our new array has already demonstrated world-class performance by generating continuous-wave irradiances of 1500 watts per square centimeter at up to a 10-percent duty cycle. Almost 100 manufacturing steps are required from start to finish; thus, careful attention to design and follow-on engineering/manufacturing issues are critical to achieving high production yield. The technology will be transferred to a commercial interest, at which point we can purchase the necessary diodes instead of manufacturing them in house. This method of working allows us to continue researching and improving the new laser-diode technology instead of concentrating on manufacturing.

The applications for diode-pumped, solid-state-laser systems are virtually endless, ranging from medical applications to laser imaging, material processing, and laser weaponry. 


\section{Heat-capacity laser demonstrates 10-kilowatt output}

With the support of the United States Army's Space and Missile Defense Command and in collaboration with industrial partners (Raytheon, Litton-Airtron, and others), we are developing high-average-power (100-kilowatt-class), diode-pumped, solid-state, heatcapacity laser technology for applications in tactical, short-range air-defense missions. The ultimate goal is an electrically powered, diode-pumped, solid-state device that can be deployed on a hybrid electric vehicle.

Recently, we completed the construction of a 10-kilowatt prototype (9-disk, neodymium-glass amplifier pumped by flashlamps) that will be installed in the Army's High Energy Laser Strategic Test Facility. This laser system was operated last year with pulse energies greater than 650 joules at a 20 -hertz repetition frequency. This generated 13 kilowatts of average power for operating durations of 10 seconds. The 1.5-megawatt input power was provided by the Nova capacitor charging system, which was upgraded for high pulse-repetition-frequency operation.

Low divergence, high-beam-quality operation will be enabled by an adaptively corrected, unstable resonator using an intracavity deformable mirror and an external wavefront sensor. Work is ongoing on the design and construction of a diode-pumped, subscale prototype, which will provide the technical basis for the scaling of the heat-capacity laser system to an average output power of 100 kilowatts. With this high-pulse-energy, heat-capacity laser development project, we continue our leadership in high-average-power, high-beam-quality, solid-state laser system technology.
Laser Technician Balbir Bhachu monitors the operation of the 10-kilowatt heatcapacity laser during low-power testing. 


\section{Business Accomplishments}

$\mathrm{E}$ ngineering continued to operate in a cost-aggressive manner in 2000. Our revenue stream, from a private-sector perspective, was approximately $\$ 450$ million (dominated by fully loaded salaries and also including equipment, facilities, and services). This represents an increase of 48 percent over the last 5-year period. Simultaneously, our operating overhead costs, after decreasing from 18 percent of revenue to 9 percent in 1999, increased by 1 percent to 10 percent, reflecting the additional costs of enhanced security and safety at the Laboratory.

The National Ignition Facility (NIF) dominated the Laboratory's business agenda, and the role of Engineering continued to escalate. Our primary business goal was to deliver on NIF milestones to meet its new baseline. We installed new leadership for both the mechanical and electronics engineering organizations within NIF; we also actively recruited our top talent to fill critical NIF skill areas. Finally, we developed a much more rigorous design review process.

At the same time, the Laboratory retained and marketed its position as a premier national security engineering R\&D organization in the country. Engineering dedicated considerable time and talent to ensuring a robust and secure nuclear stockpile, and we expect an upsurge in defense work in 2001. We also improved the cost efficiency of our underground subcritical testing. Several national publications featured our technical work.

To promote new business opportunities and to effect technical advances, we named a corps of new leaders: a chief scientist, a chief engineer, and a deputy associate director for new initiatives. These leaders will help us take stronger roles both inside and outside the organization.

\section{Human capital pursuits}

Being able to work at the cutting-edge-whether in lasers, defense, security, energy, or a biomedical field—is what helps us retain and attract engineering talent. In 2000, our attrition rate jumped to over 12 percent (resignations and retirements) from our historical average of 5-7 percent. While this is still a low rate compared to the local high-tech-industry attrition rate, it has meant ramping up our recruiting and paying attention to retention. We are striving to create a more satisfying work environment that appeals to our current employees, as well as potential recruits. 
The Laboratory's Critical Skills Retention Allocation enabled us to increase raises in certain areas of hotly demanded skills. Another thrust was internal communications. We started a semimonthly, electronic newsletter, with readership now at over 90 percent of Engineering. In addition, we built a new internal Engineering Website.

To prepare for the escalating retirements in an aging workforce as well as provide new opportunities for our employees, we launched our Leadership Development Program. We also chartered a vigorous Project Management Initiative to help our employees take on major roles in big projects, as well as ensure the success of megaprojects such as NIF. Employees began taking classes onsite through the Project Management Institute. Both programs are described in the New Ventures section.

Now we are working on our first Engineering job fair, to be held in 2001. Our goal is to appeal to commuters who are tired of the traffic gridlock to Silicon Valley and are looking for a high-tech employer with job stability. Also next year, we will receive results from our Laboratory employee survey. We plan to redirect our retention efforts in terms of work-life issues and communications based on survey results.

\section{Technology advances}

The best engineering technologies will attract the best people. In 2000, 31 of the 98 patents awarded to the Laboratory involved Engineering personnel as inventors or coinventors. Many of our technical advances originate in our five technology centers. Each center's mission is to sustain our competitive edge, creating products or systems that are technically one-of-a-kind. Our Engineering Research, Development and Technology Report discusses the work, demonstrating that we accomplished ground-breaking work in modeling, lasers, microtechnology, and imaging.

\section{Safety and security upgrades}

The new National Nuclear Security Administration continued to increase demands for the Laboratory as a whole to improve in safety and security, particularly cybersecurity. Several verification teams from headquarters were onsite during 2000 to validate that new and improved measures were in place.

Over the past few years, our safety record in Engineering (and throughout the Laboratory) improved significantly. The cost index (a metric used to measure the combined frequency and severity of injuries) improved from 15 in 1998 to 7 in 1999, but increased to 9 in 2000 with one major onsite bike accident. We have seen a reduced frequency in the number of lost and restricted work days this year. This overall downward trend represented an approximate 50-percent reduction in necessary costs caused by safety-related incidents.

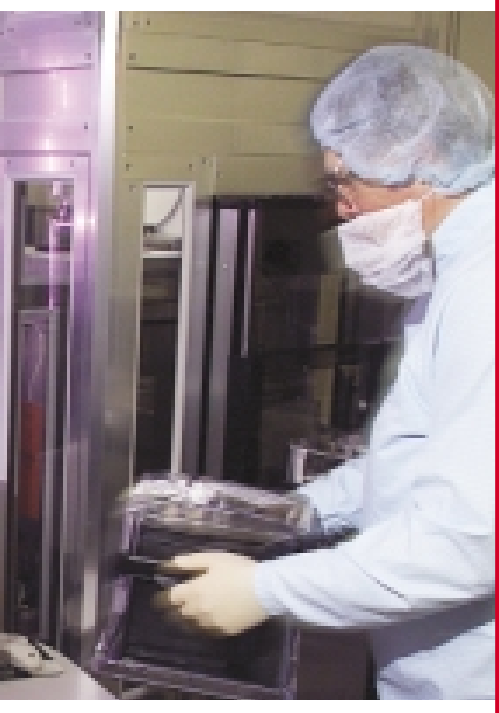

At left and above, Engineer Courtney Davidson loads a cassette of mask substrates into the lowdefect multilayer deposition system for extreme ultraviolet lithography. Defect-free multilayers of molybdenum and silicon are required to fabricate the master pattern masks. 


\section{New Ventures}

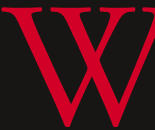

hile our five Technology Centers are responsible for pioneering breakthroughs in science and engineering technologies, we must create provocative programs and initiatives that cut across the organization.

In 2000, we focused on three cross-cutting ventures:

- Exploring fresh business approaches. Our new deputy associate director for new initiatives is responsible for enabling new programs and developing new funding sources for Engineering.

- Championing a new initiative to ensure excellence in project management and systems engineering. Our new chief engineer heads the Project Management Initiative to ensure high standards of engineering in all projects.

- Launching Engineering's first Leadership Development Program. The program, which features a partnership with the Director's Office, Human Resources, and Engineering, has already captured the vigor and fresh ideas of our emerging leaders. In the last six months, our new leaders have proposed a dozen ventures to fill gaps and correct inefficiencies, excite new employees, and appeal to future recruits.

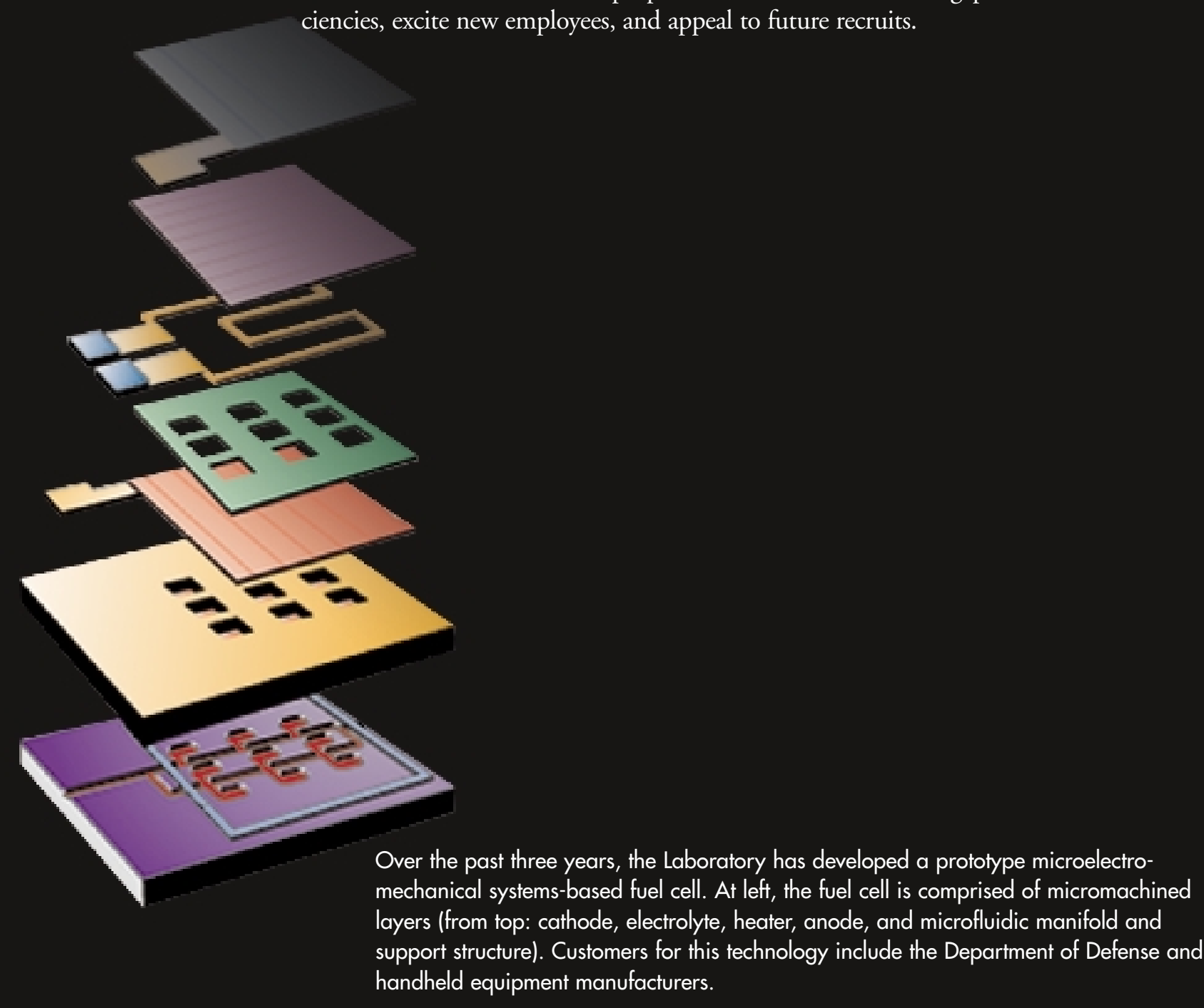




\section{Special initiatives}

Beginning in FY01, Engineering increased attention on investigating projects that may lead to future programs for the Laboratory. The new role of deputy associate director for new initiatives was created to lead this activity. The primary goals are to maximize the extent to which Engineering's technologies and capabilities can enable new programs for the Laboratory's programmatic organizations; attract licensing, royalty, and other types of income in areas of Engineering responsibility (for example, commercializing Engineering patents); and enable and broaden support for Engineering services and technology development activities through new funding sources.

Over 50 new initiatives have been identified and are being pursued. Many of these have already achieved funding. A few examples of these are shown below.

The Laboratory was recently awarded a Defense Advanced Research Projects Agency contract to explore building automated sensors for Department of Defense soldier-in-the-field applications. The Laboratory will concentrate on miniaturized radar sensors using Engineering's homodyne radar systems.

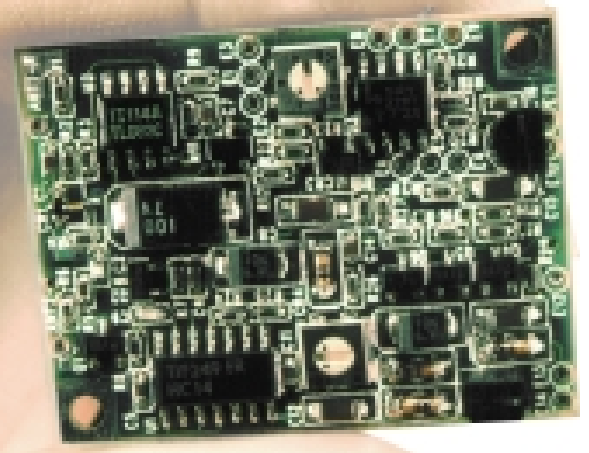

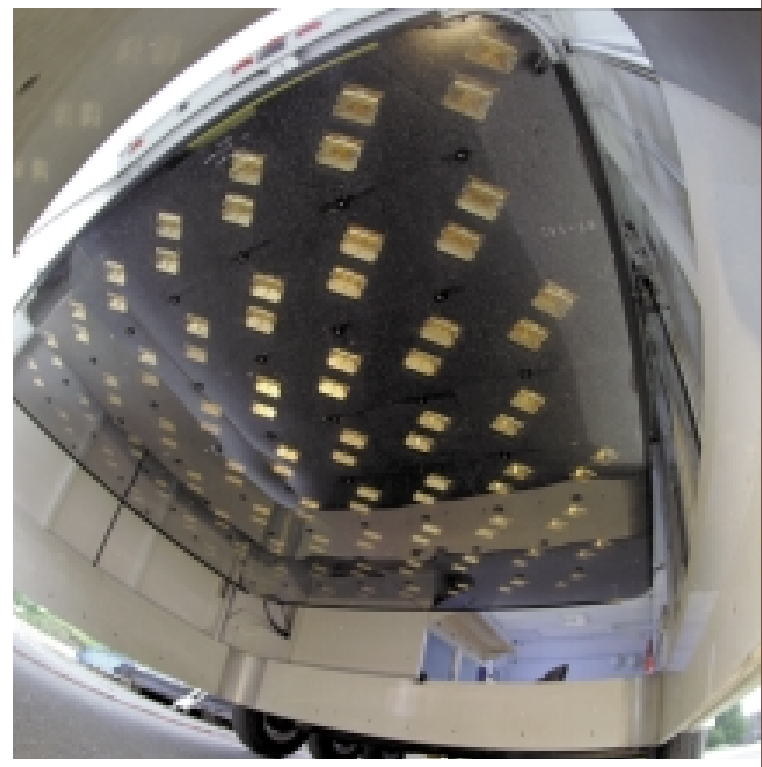

We have begun work on the HERMES-2 program, funded by the Department of Transportation. HERMES-2 is expected to result in a commercializable bridge and highway inspection system, building on the success of the HERMES-1 systems. A fisheye-lens view of the HERMES-1 radar modular array is shown. 


\section{Project management and systems engineering initiative}

With the goal of developing and facilitating the accelerated adoption of superior systems engineering and project management practices across Engineering and the Laboratory, we launched our project management and systems engineering initiative. The initiative focuses on five major areas: outstanding program support, targeted development and recognition, state-of-the-art tools, best practices, and superior systems management. Our chief engineer is leading the initiative.

Substantial momentum has started building with the formulation of a long-term strategy that includes a detailed project plan and Engineering division action plans. A 3-day introductory project management training course was held for 75 Laboratory employees (with 25 employees signed up for the next session), and an 8-week Project Management Institute training course was held for over 100 candidates across the Laboratory. Standards development is also underway; a team of specialists began working on an expanded, integrated, and online rewrite of Engineering's Policies and Procedures Manual. Finally, a project management review procedure was completed, piloted, and implemented within Engineering's divisions.

In terms of project management, implementing the initiative is the first step in helping the Laboratory become known as best-in-class of integrated R\&D institutions in the country. We plan to improve our cost, schedule, and technical performance, while creating a common frame of reference and vocabulary, increasing our credibility, and advancing the careers of our participants.

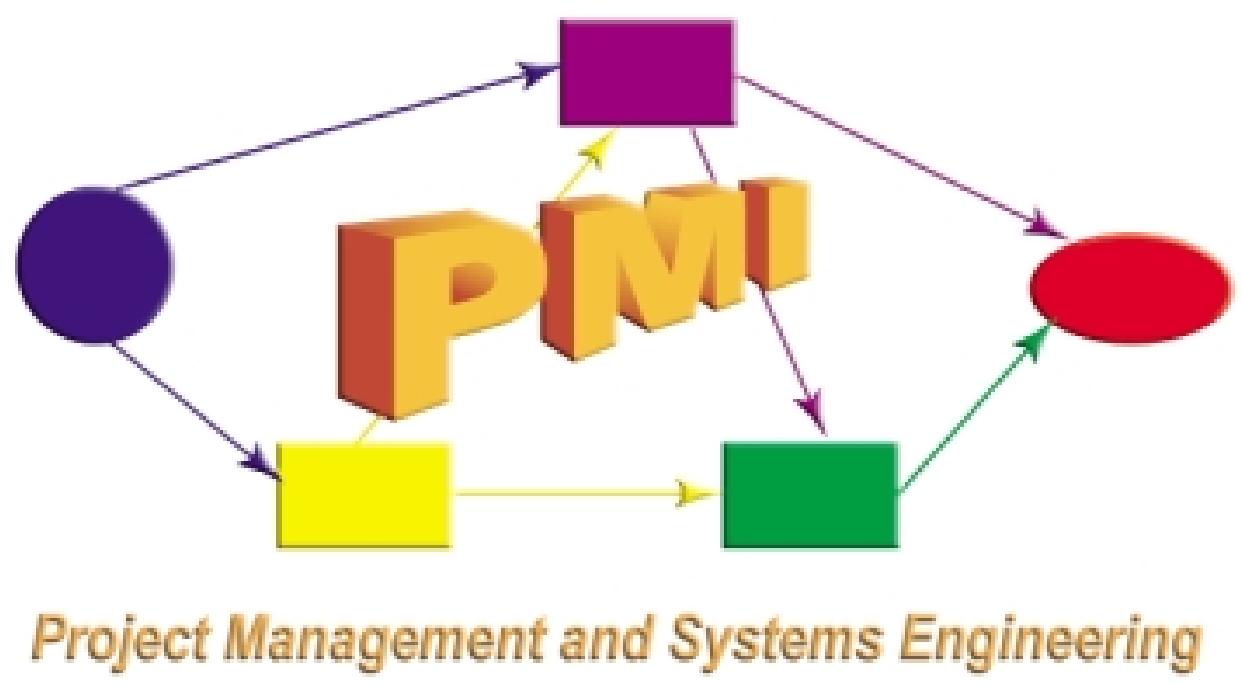

The Project Management and Systems Engineering Initiative reflects interrelated areas of project management practices. 


\section{The Leadership Development Program}

Recognizing that we must foster leadership-both to enrich the organization and to offer opportunities for employees - last year we pioneered the Engineering Leadership Development Program (LDP). The program was designed to build a pool of trained younger employees to be ready to take on leadership tasks as openings occur; to offer opportunities for younger employees to develop in lead roles, including line, technical, program, project, and institutional management; and to provide advanced training for current leaders within Engineering.

The pilot program began with engineers nominated by their divisions. Two groups of emerging leaders have now been meeting - one selected in January 2000, the second in June 2000. A third group is planned for early 2001. A similar program is being developed for administrators and technicians, with kickoff anticipated in early 2001.

The Engineering LDP has been linked with the Leadership Lecture Series, sponsored by the Laboratory Director's Office and Human Resources, which offers various leadership courses to Laboratory personnel. LDP participants typically attend special workshops with lecturers from the series, geared to Engineering-related leadership issues. In 2000, Jim Kouzes presented Leadership Challenge, Hendrie Weisinger presented Emotional Intelligence, Terry Pearce presented Leading Out Loud, David Tulin presented Emotional Intelligence Applied to Diversity, and Carol Kinsey Goman presented Thriving on Change.

Engineering hopes the LDP will be valuable to Engineering employees, whatever their career track, and to be career-supporting versus career-determining.

Our emerging leaders reflect a diversity of talent and fresh ideas. This year 40 completed the program, and we expect another 40 in 2001. 


\section{Honors and Awards}

he wealth of Engineering is in its people. In 2000, we continued to be honored by professional societies, universities, the government, and technical organizations. In addition, we performed leadership roles in sponsoring technical conferences nationally and globally.

Overall, Engineering holds almost 1000 patents. This year, we garnered another 31 .

Of special interest this year is our waste inspection tomography team, which earned an R\&D 100 Award, considered the "Oscar of Invention." The new technology, combining waste inspection tomography with nondestructive assay, , can "see" into opaque drums and without opening them, safely determine the waste mix, including the amount of radiation inside.

Across the nation sit 600,000 barrels of radioactive waste. The contents are often unknown because many of the barrels were sealed decades ago. These images show the vehicle employed for inspecting the drums as well as the scan of the contents of three sample drums, which results from using waste inspection tomography with nondestructive assay. This new technology earned a prestigious R\&D 100 Award for its Engineering inventors. 


\section{R\&D 100 Award: WIT-NDA drum scanning project}

The Waste Inspection Tomography for Nondestructive Assay system garnered a prestigious R\&D 100 Award for the Laboratory and its commercial partner, Bio-Imaging Research, Inc. This award is presented annually by $R \& D 100$ Magazine to "the most technologically significant new products and processes of the year." The system was developed by a team of engineers and physicists, headed by Engineering's G. Patrick Roberson and Harry E. Martz, Jr.

\section{Professional honors and offices}

American Association of Engineering Societies

Chairperson, Executive Committee: Theodore Saito

American Institute for Aeronautics and Astronautics Senior Members: Robert M. Ferencz, Robert J. Sherwood, Roxana M. Greenman

American Institute of Chemists

Fellow: Suzanne B. Monaco

American Nuclear Society

Secretary-Treasurer, Fusion Energy Division: Sandra J. Brereton; Chairperson, Executive Committee, Robotics and Remote Systems Division: Albert Disabatino; Executive Committee Member, Fusion Energy Division:

Jeffery F. Latkowski

American Society for Nondestructive Testing Fellow and Member of the Board of Directors: Graham Thomas

American Society of Mechanical Engineers Session Chair, International Conference on Nuclear Engineering: Sandra J. Brereton; Executive Committee Member and Elected Chair of IMECE Subcommittee, Microelectromechanical Systems Subdivision: Abraham P. Lee; Associate Technical Editor (Journal of Energy Resources Technology), Chairman (Advanced Energy Systems Division), and Committee Member (International Program Committee, Energy Systems Design and Analysis Conference, Istanbul, Turkey): Salvador Aceves-Saborio; Committee Member, International Advisory Committee, International Conference on Energy Research and Development, Kuwait: Salvador Aceves-Saborio
American Welding Society Certified Welding Inspector: Edward W. Russell

Cambridge Health Institute Scientific Advisory Board Member: Abraham P. Lee

Department of Energy Chairman of Working Group, Software Quality Assurance Subcommittee of the Nuclear Weapons Complex Quality Managers: Edward W. Russell

The Institute of Electrical and Electronics Engineers Senior Member, Nuclear Science Symposium General Chairman,

Nuclear Science Symposium Site Selection Committee, and Nuclear Science Symposium Contract Negotiator: Anthony D. Lavietes; Senior Member and Nuclear Science Symposium/Medical Imaging Conference Treasurer and Senior Member: Guy A. Armantrout; Senior Member: Gerald J. Burke; Peer Reviewer, Electronics Letters, Transactions on Nuclear Science: Steve P. Swierkowski; Technical Program Committee Chair, 2002 Conference on Ultra Wideband Technologies and Systems (invited to present tutorial on ultrawideband, 2000 Radio and Wireless Conference): Rexford M. Morey; Chairman (Nuclear and Plasma Sciences Society, Fusion Technical Committee), General Chairman, 20th Nuclear and Plasma Sciences Society Symposium on Fusion Engineering: Richard J. Foley

Institute of Environmental Sciences and Technology Senior Member: Valerie S. Roberts

International Center for Applied Thermodynamics Committee Member, Technical Advisory Committee, International Journal of Applied Thermodynamics: Salvador Aceves-Saborio 
International Journal of Energy

Board Member, Editorial Board: Salvador Aceves-Saborio

National Aeronautics and Space Administration Advisory Board Member, Advanced Environmental Monitoring and Controls Report, and External Advisory Board Member, Joint Initiative on Detection Methods for Molecular Signatures: Abraham P. Lee

Society of Manufacturing Engineers

Senior Member: Elon Ormsby

Society of Mexican American Engineers and Scientists National Vice President: Jose M. Hernandez

SPIE-The International Society for Optical Engineering International Symposium on Micromachining and Microfabrication, Conference Chair for Micro-OptoElectromechanical Systems and Miniaturized Stems: Peter Krulevitch

United States Association for Computational Mechanics Minisymposium Organizers for National Congress: Robert M. Ferencz and Carol G. Hoover

Selected awards and honors

California Polytechnic State University, San Luis Obispo Aerospace Engineering Department Outstanding Recent Alum Award: Roxana M. Greenman

Department of Energy DOE NN-50 Outstanding Performance Award: Jose M. Hernandez

Engineer Roxana Greenman was recognized as an outstanding recent alum at California Polytechnic State University's Aerospace Engineering Department.

The Institute of Electrical and Electronics Engineers Third Millennium Medal Award for Valued Services and
Society of Mexican American Engineers and Scientists Medall de Oro: Jose M. Hernandez

\section{Patents}

Active Alignment/Contact Verification System William M. Greenbaum

Cone Penetrometer Fiber-Optic Raman Spectroscopy Probe Assembly

Kevin R. Kyle, Steven B. Brown

Durable Silver Coating for Mirrors

Jesse D. Wolfe, Norman L. Thomas

Formulation of Nanofilament Field Emission Devices Jeffrey D. Morse, Robert J. Contolini, Ronald G. Musket, Anthony F. Bernhardt

Frustrated Total Internal Reflection Acoustic Field Sensor Jeffrey S. Kallman

Fusion Bonding and Alignment

Harold D. Ackler, Stefan P. Swierkowski, Lisa A. Tarte, Randall K. Hicks

High-Energy, Low-Frequency Ultrasonic Transducer Albert E. Brown

Hydrodynamic Blade Guide

Kenneth L. Blaedel, Pete J. Davis, Charles S. Landram

Low Work Function, Stable Compound Clusters and Generation Process

Long N. Dinh, Mehdi Balooch, Marcus A. Schildbach, Alex V. Hamza, William McLean II

Method and System for Normalizing Biometric Variations to Authenticate Users from a Public Database and Ensure Individual Biometric Data Privacy

Robert S. Strait, Peter K. Pearson, Sailes K. Sengupta Contributions: Gerald J. Burke
Method to Adjust Multilayer Film Stress-Induced Deformation of Optics Eberhard A. Spiller, Paul B. Mirkarimi, Claude Montcalm, Sasa Bajt, James A. Folta 
Micro Devices Using Shape-Memory-Polymer Patches for Mated Connections

Abraham P. Lee, Joseph P. Fitch

Microbenchtop Optics by Bulk Silicon Micromachining Abraham P. Lee, Michael D. Pocha, Charles F. McConaghy, Robert J. Deri

Microfabricated Therapeutic Actuators and Release Mechanisms Therefore

Abraham P. Lee, Joseph P. Fitch, Daniel L. Schumann, Luiz Da Silva, William J. Benett, Peter A. Krulevitch

Microminiature Gas Chromatograph Column Disposed in Silicon Wafers

Conrad M. Yu

Microsonicator for Spore Lysis

Robin R. Miles, Phillip Belgrader, Shanavaz L. Nasarabadi

Miniature X-Ray Source

James E. Trebes, Perry M. Bell, Ronald B. Robinson

Optical Key System

Karla G. Hagans, Robert E. Clough

Opto-Acoustic Throbolysis

Peter Celliers, Luiz Da Silva, Michael Glinshy,

Richard London, Duncan Maitland, Dennis Matthews,

Pat Finch

Plasma-Assisted Catalytic Storage Reduction System Bernardino M. Penetrante, George E. Vogtlin, Bernard T. Merritt, Raymond M. Brusasco

Release Mechanism Utilizing Shape Memory

Polymer Material

Abraham P. Lee, M. Allen Northrup, Dino R. Ciarlo,

Peter A. Krulevitch, William J. Benett

Shape Memory Polymer Gripper with a

Release Sensing System

Duncan J. Maitland, Abraham P. Lee, Daniel L. Schumann, Luiz Da Silva

Submicron Patterned Metal Hole Etching Anthony M. McCarthy, Robert J. Contolini, Vladimir Liberman, Jeffrey Morse
System and Method for Preconcentrating, Identifying, and Quantifying Chemical and Biological Substrates

Conrad M. Yu, Jackson C. Koo

T-Load Microchannel Array and Fabrication Method Stefan Swierkowski

3-D Laser Patterning Process Utilizing Horizontal and Vertical Patterning

Vincent Malba, Anthony F. Bernhardt

Three-Tooth Kinematic Coupling

Layton C. Hale

Ultracompact Marx-Type High-Voltage Generator

David A. Goerz, Michael J. Wilson

Waveguide Detection of Right-Angle-Scattered Light in Flow Cytometry

Raymond P. Mariella, Jr.

Vacuum Compatible Miniature CCD Camera Head Alan D. Conder

Zero Dead Volume Tube to Surface Seal

William J. Benett, James A. Folta

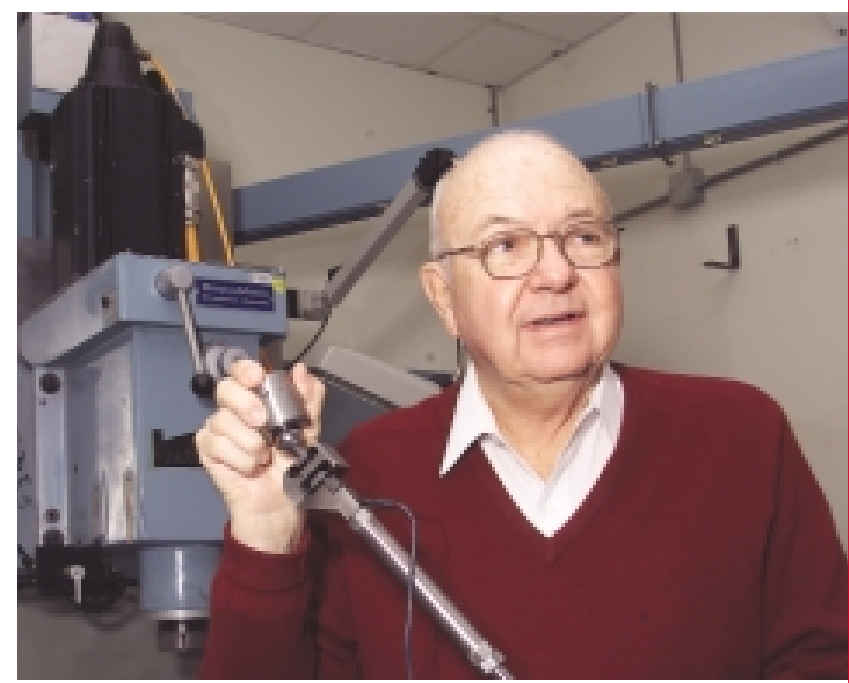

The "forefather of precision engineering," Jim Bryan (now retired), was named one of the six "Heroes of Manufacturing" by Fortune magazine for his design of the telescoping ball bar, which measures machine tools for accuracy. During the past decade, literally billions of dollars worth of machine tools have been tested with the ball bar. 


\section{Future Priorities}
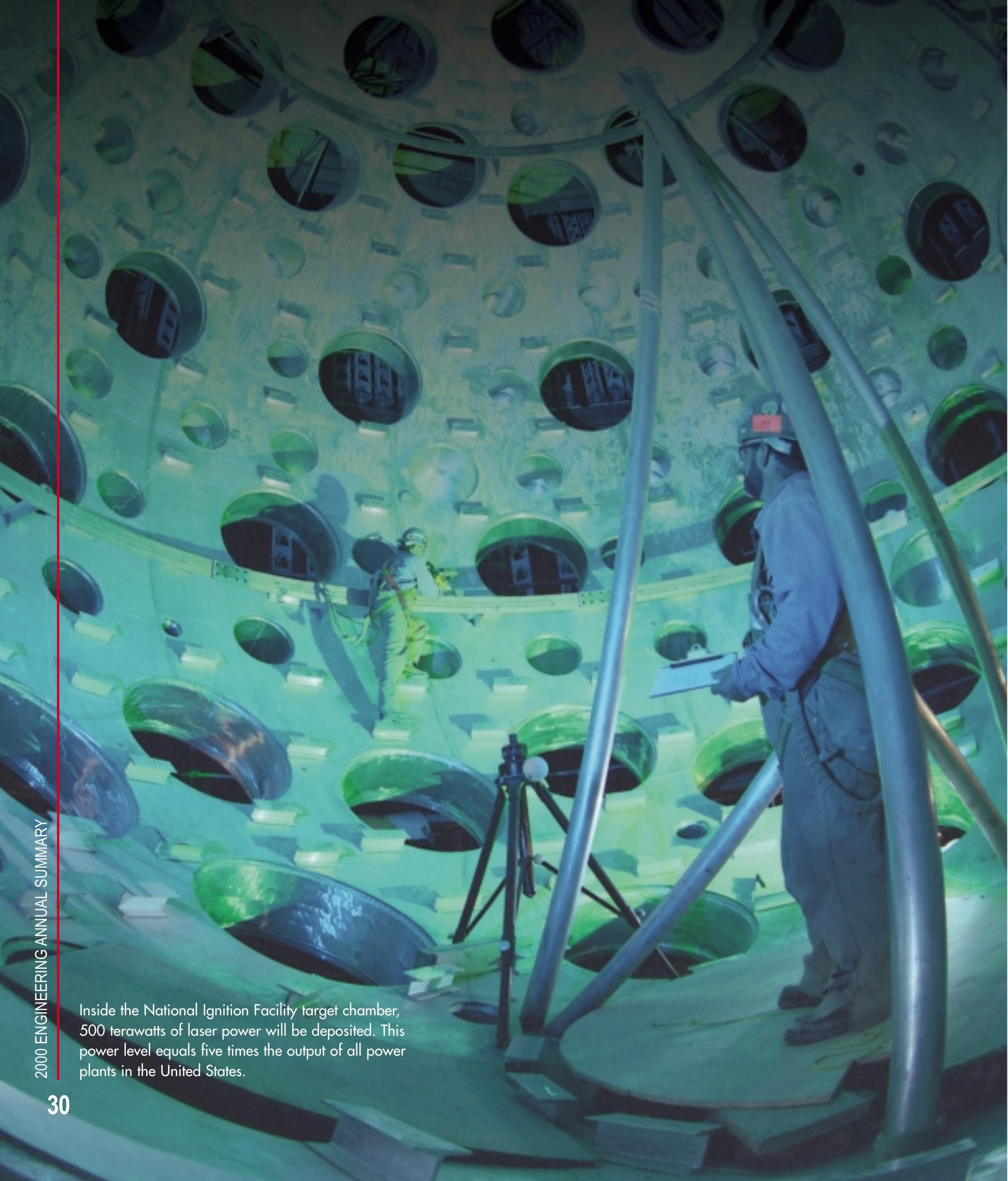
$\mathrm{E}$ ngineering is highly regarded as the backbone of the Laboratory, the organization that provides talent when programs require it, reassigns returning talent when programs are completed, and develops talent to meet future priorities. In recent years, we have relied on a relatively stable employee base to meet our technical milestones, but Engineering has slowly decreased in size from a high of 3000 employees 15 years ago to our current level of about 2000 .

Now that we have higher profile programs, growing attrition, an aging workforce, and new skills requirements, we must refocus. It is vital to build a larger, more robust workforce that can meet the demanding timeline of the National Ignition Facility (NIF), fulfill the technical requirements of defense and national security, and propel the frontiers of new science and technologies. Therefore, our top priorities for 2001 are:

- Escalate workforce hiring. Our goal is to hire nearly 300 technical people this next year. To do this, we must ensure Engineering is visible on the national engineering scene and in the press.

- Keep NIF on track. With the new baseline, we must ensure Engineering delivers on schedule and within budget. This involves supplying sufficient talent as well as executing sound project management discipline.

- Assume W80 refurbishment responsibilities. Again, we will require new talent and careful planning as we take a leadership role on the life extension program for the W80 weapon system. We also must ensure a smooth transfer of engineering information for this system from its designer, Los Alamos National Laboratory.

- Execute effective succession planning. We estimate we will lose one-quarter of our workforce to retirement by 2005. We must ensure the retention of existing expertise and the hiring of new talent in critical skills areas, particularly the weapons arena.

- Begin the reinvestment process in people, facilities, and equipment. While NIF offers considerable high-tech capital equipment and facilities, other areas of Engineering must upgrade our "stable of workhorses." We have recently concentrated on state-of-the-art laboratories and machinery, so now is the time to invest in our more traditional equipment and facilities.

- Continue the momentum established last year on our two major initiatives-the Leadership Development Program and the Project Management Initiative. With an aging workforce, there is room for leadership. We need to ensure our employees are ready to assume the responsibility for expertly managing people and projects. 


\section{Engineering statistics}

Engineering five-year revenue and cost profile (modeled from a private-sector perspective)

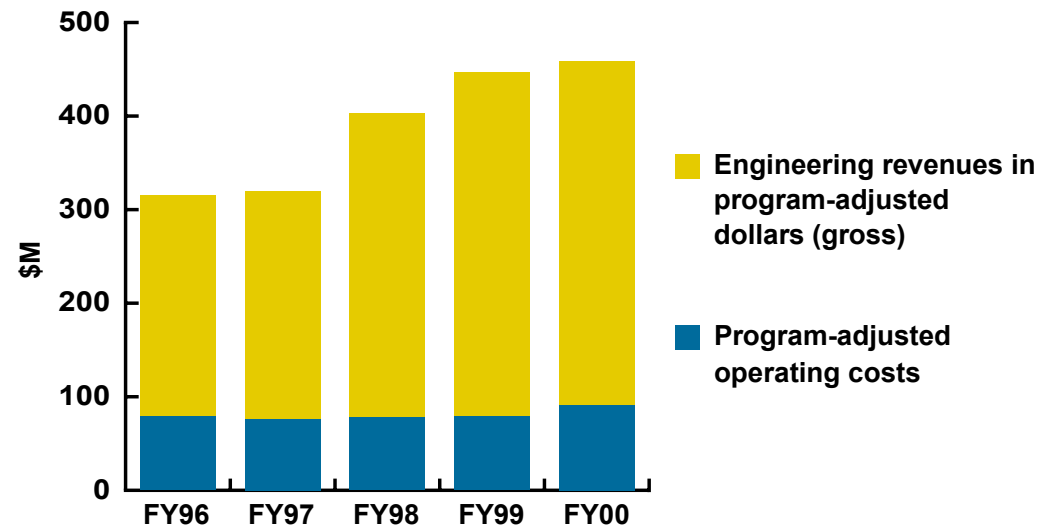

\section{Engineering five-year operating expenses} (program-adjusted dollars)

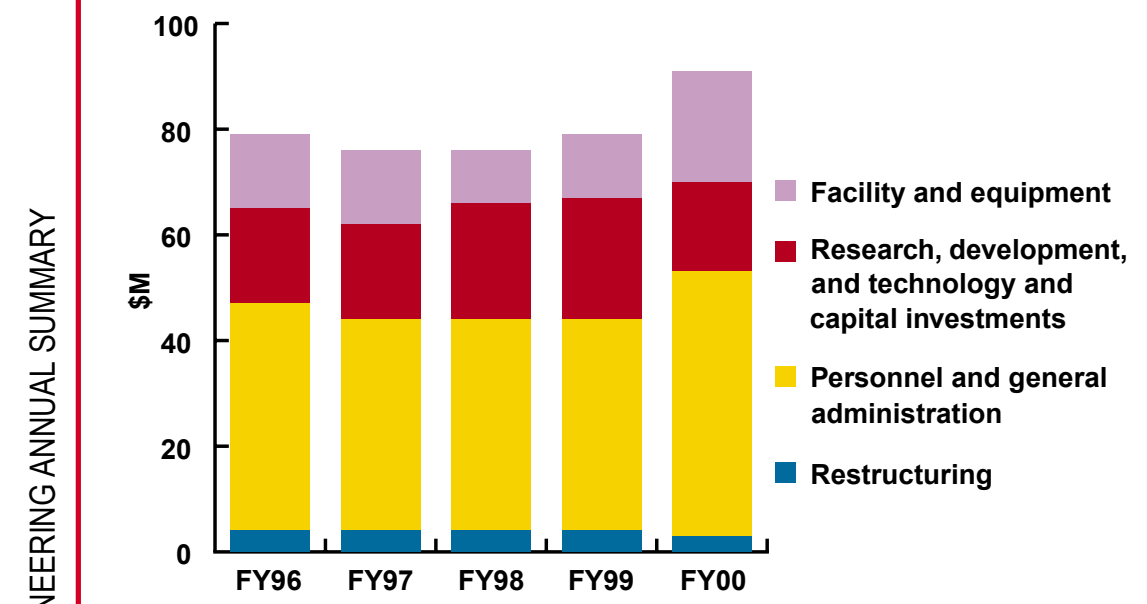

\section{Engineering staffing profile (as of $12 / 31 / 00$ )}

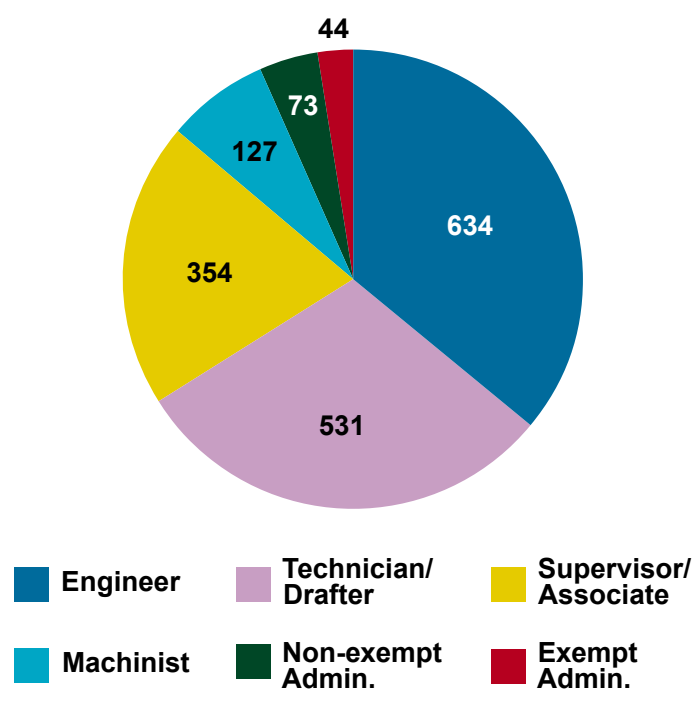

Engineering staffing growth (as of $12 / 31 / 00$ )

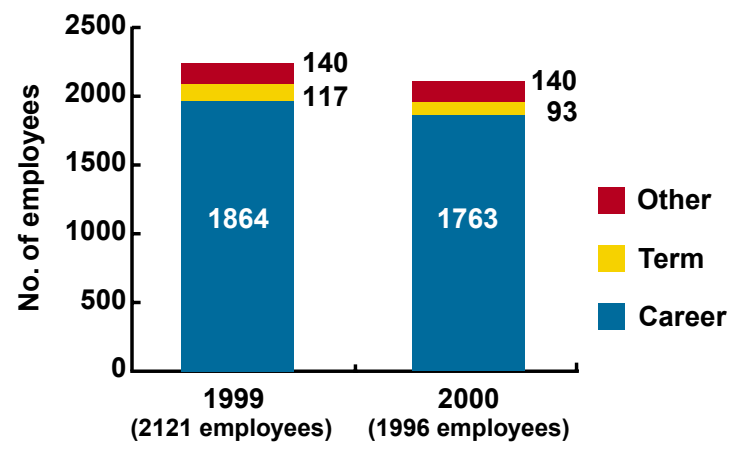




\section{Laboratory statistics}

\section{Laboratory five-year revenue profile}

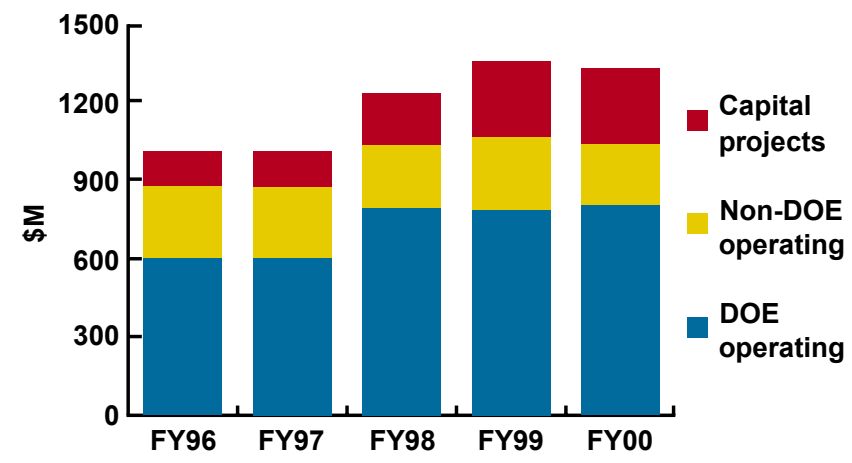

\section{Laboratory staffing profile (as of $12 / 31 / 00$ )}

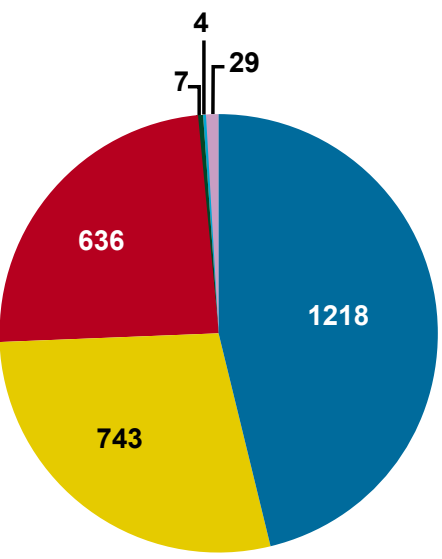

Scientists and Engineers

(2637 employees)

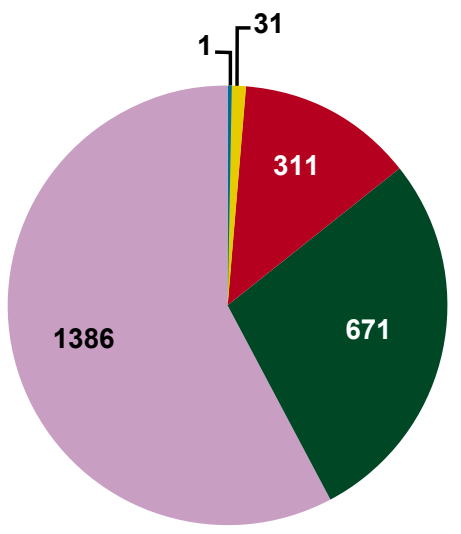

Technical and Crafts (2400 employees)

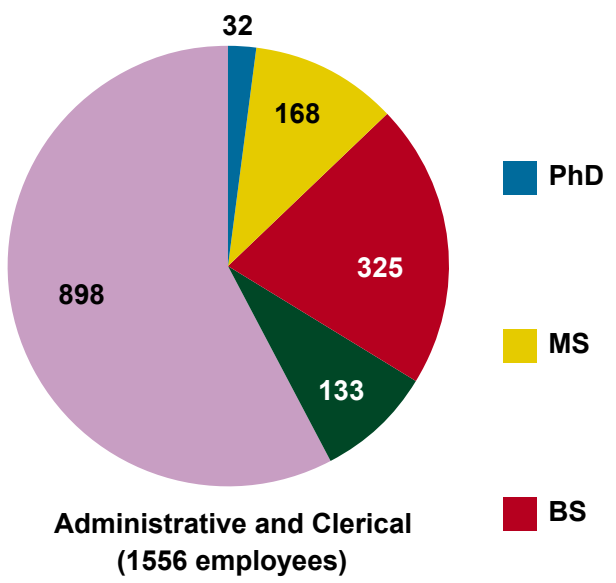

AA

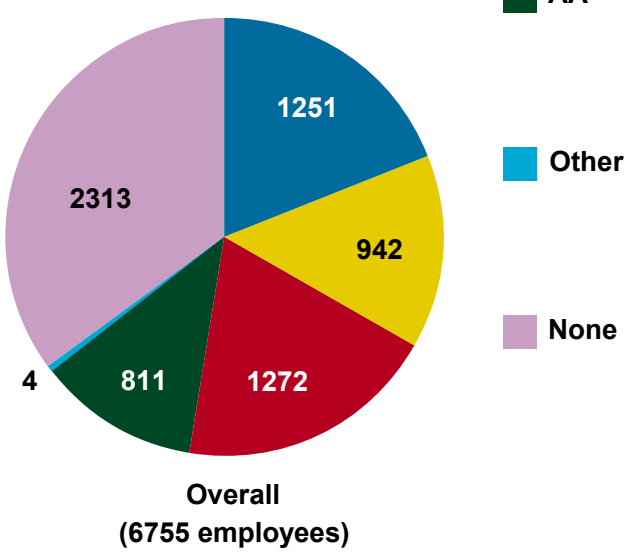




\section{GNGINEBRING}

University of California

Lawrence Livermore National Laboratory

P.0. Box 808, L-151

Livermore, CA 94551

www-eng.IInl.gov

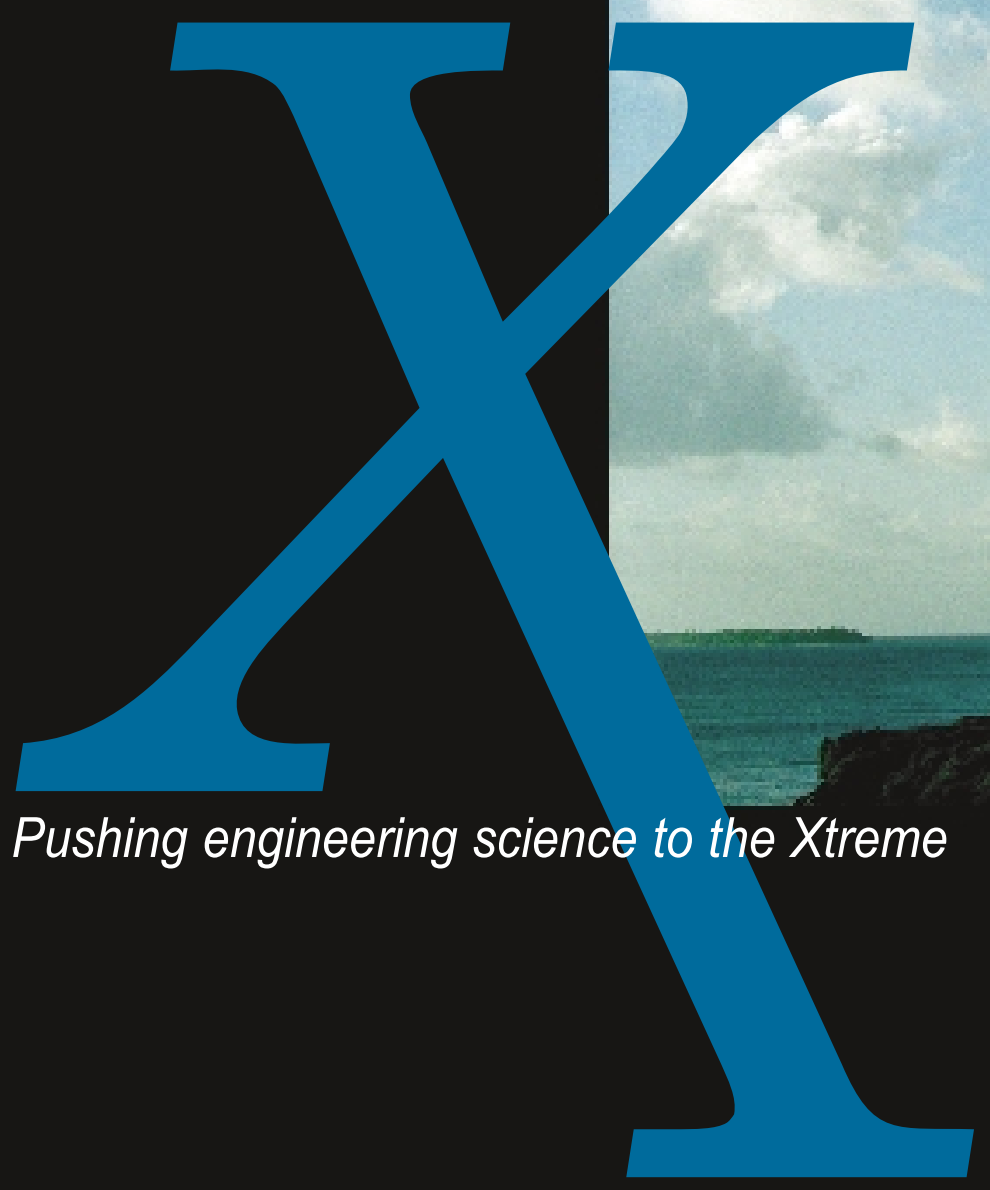

